\title{
Elementos para el Estudio de la Cultura
}

\author{
Ignacio Farías Hurtado. Sociólogo. Universidad Católica de Chile. Doctorando en \\ Antropología Social y Cultural. Universidad de Barcelona-España \\ ifh@hotmail.com
}

\begin{abstract}
En Modernity at Large (1996: 46) Arjun Appadurai plantea a partir de tres metáforas los requisitos que una teoría antropológica debería cumplir para dar cuenta de los procesos culturales en un mundo globalizado. Las formas culturales, señala, deben comenzar a ser pensadas en términos fractales, reemplazando la idea euclidiana de conjuntos con límites y estructuras substancialmente definidos. Las múltiples similitudes y superposiciones de estas formas fractales, añade, deberían observarse a su vez desde una perspectiva politética. Además, sería necesario reconocer, con herramientas analíticas similares a las de la teoría del caos, cómo estas formas fractales se concretan en múltiples y diversas interacciones humanas, y cómo a su vez forman un sistema estable, simple, aun cuando opere con alta complejidad.
\end{abstract}

Geertz (1973: 19) ha señalado ya la cautela con que la antropología debería tomar siempre el auge de grande idées como éstas: "La segunda ley de la termodinámica o el principio de la selección natural o el concepto de motivación inconsciente o la organización de los medios de producción no lo explica todo ..., pero sin embargo explica algo; de manera que nuestra atención se dirige a aislar ese algo". Por lo mismo, las metáforas de Appadurai para una teoría de la cultura global deben ser entendidas como tales y nada más. Eso implica, sin embargo, que no es posible desdeñar su valor; por el contrario tales metáforas deben tomarse como instrumentos para la búsqueda y para el señalamiento de un punto de partida nuevo para el desarrollo de una teoría científica de la cultura. Ahora bien, su valor parece encontrarse más en la indicación de aquello que un estudio de la cultura no debe presuponer, y es necesario empezar por ahí. En ese sentido pensar críticamente en la idea de la cultura como conjunto euclidiano entrega una pauta para rechazar todo enfoque que declare la cultura como un 'algo' que posee unas determinadas características, y en ese sentido resulta necesario distanciarse de definiciones como habitus, ethos, mundo de la vida, etc. De la misma manera la observación de la cultura como unidad, sea esta una unidad sistémica o estructural, sea ónticamente dada, dialécticamente alcanzada a través de la historia o simplemente lógica, deben ser también superadas para atender a ese carácter politético de la cultura que señala Appadurai. Pero tampoco se trata entonces de pensar en la cultura como un espacio de múltiples y diversas representaciones mentales independientes al acontecer del mundo. La cultura, poéticamente figurada como 'conjunto politético estable de formas fractales fugaces', encontraría en el espacio de la interacción su umbral de emergencia.

Como muchos otros, Appadurai observa que una ruptura en la forma de la modernidad habría acontecido en algún momento entre los años 70 y 80 . No se trata en su caso de una declaración del advenimiento de la pos-modernidad, sino más bien del señalamiento de una nueva etapa, tal como por ejemplo lo hace Beck en La sociedad del riesgo cuando señala un proceso reflexivización de la modernidad. En el caso de Appadurai, sn embargo, el concepto clave no es tanto reflexividad como imaginación: "La imagen, lo imaginado, el imaginario -son todos términos que nos dirigen a algo crítico y nuevo en los procesos culturales globales: la imaginación como una práctica social" (1996: 31). La centralidad de la imaginación en el mundo contemporáneo radicaría en que constituiría el 
medio privilegiado para anexar lo global al espacio de las prácticas locales, permitiendo así una actualización diferenciada de la cultura global en el espacio de las interacciones. De esta forma, las sugerencias indicadas por Appadurai para el desarrollo de un concepto de cultura son entonces limitadas a la forma contemporánea de la cultura.

He aquí nuestro primer problema, puesto que encontramos muy incitantes las sugerencias de Appadurai para pensar en la cultura desde un marco científico aplicable también a otros momentos históricos. No se trata entonces de contra-argumentar señalando junto con Wallarstein, Bourdieu o Luhmann la continuidad estructural de la modernidad como un proceso de diferenciación y globalización que se remonta a ya varios siglos, a fin de poder extender históricamente estas sugerencias. A pesar de que tales argumentaciones parecen bastante más acertadas que aquellas que declaran constantemente nuevos puntos cero, seguir tal camino implicaría hacerle el quite a la cuestión de largo alcance que aquí nos preocupa: sugerir unos puntos teóricos de partida para el estudio de la cultura, sea en la sociedad y en el momento que sea. Siguiendo el consejo de Geertz respecto a la prudencia necesaria frente a las grande idées, habría que centrar entonces la atención en los principios teóricos implícitos en la posición de Appadurai para, una vez aislados, comenzar nuevamente.

Si es la observación del auge de la imaginación como práctica social clave en el mundo contemporáneo lo que ha llevado a Appadurai a formular aquella metáfora de la cultura que tanto nos gusta, resulta primero necesario clarificar a lo que con tal concepto refiere. La característica principal que definiría la imaginación ya se ha señalado: constituye el espacio a través del cual "los individuos y grupos buscan anexar lo global en sus propias prácticas de lo moderno" (1996: 4). No se trata a juicio de Appadurai ni de un espacio para la emancipación individual o grupal, ni de un espacio enteramente disciplinado y sometido al poder, sino de un espacio de contestación, de reformulación de lo global a partir de lo local. Su centralidad en la modernidad radicaría en que la imaginación pasa a ser parte de la vida cotidiana, despegándose así de los límites definidos por los espacios del mito, del rito y del arte. En ese sentido, señala Appadurai, la imaginación debe ser distinguida respecto a la mera fantasía, pues a diferencia de esta última se encuentra orientada hacia el mundo, produciendo en gran medida lo social. Esta orientación de la imaginación hacia el mundo adquiere mucho mayor relevancia en la medida que no opera simplemente a nivel individual, sino a nivel grupal, formando comunidades. Estos procesos colectivos de imaginación resultan entonces como una suerte de 'para-sí' supraindividual.

Tal definición de la imaginación remite directamente a un principio sociológico más amplio: la observación. De ésta es posible señalar lo mismo que Appadurai señala respecto a la imaginación. La observación constituye siempre una diferencia -como la diferencia local global-, que permite la reintroducción de la diferencia en el lado que se indica y que es el lado desde el cual se opera -como es ese anexamiento de lo global en lo local-. Por otra parte, y tal como ha señalado Luhmann, lo social es única y exclusivamente comunicaciones, y toda comunicación tiene la forma de una observación. En ese sentido no debe sorprender el alto rendimiento que pueda alcanzar la imaginación en el mundo contemporáneo, pues constituye una forma específica de observación y de comunicación que evidentemente puede formar parte de la vida cotidiana y producir en gran medida lo social. De la misma manera, que la imaginación adquiera relevancia social en la medida que se constituye a un nivel supraindividual resulta del hecho de que la comunicación se constituye a un nivel supraindividual. Podemos entonces dejar descansar la imaginación de Appadurai, dejando abierta la posibilidad de que 
efectivamente se trate de una característica propia de la modernidad, para comenzar a pensar en la cultura desde estos otros principios: observación y comunicación.

Cualquier formulación teórica que tome los conceptos de observación y comunicación como hasta aquí han sido esbozados puede reconocerse rápidamente como en directa continuidad con la teoría de la sociedad elaborada por Niklas Luhmann. Sin embargo, la definición de un concepto de cultura, así como la indicación de su papel específico en la sociedad, aparecen como dos cuestiones no suficientemente elaboradas en la teoría de sistemas autopiéticos. La apuesta principal a partir de la cual se elaboran las siguientes consideraciones radica en que un análisis en profundidad de la distinción conceptual propuesta por Luhmann bajo los términos de autobservación y autodescripción de la sociedad permitirá definir con extrema precisión el papel de la cultura.

La primera parte de este documento, 'Cultura y Teoría de Sistemas', apunta fundamentalmente a señalar la preponderancia de primer orden que tendría el concepto de cultura en la actual teoría de sistemas, en la medida que en ella -como en ninguna otra teoría- se trata el problema de la observación de la sociedad sobre sí misma. Para comprender con claridad de lo que la teoría habla cuando habla de observación de la sociedad sobre sí misma, proponemos la distinción entre autobservación de la sociedad y heterobservación de la sociedad. Esta distinción, que se puede deducir del especial carácter de la sociedad en cuanto sistema, será ligada a una serie de otras distinciones propuestas por Luhmann como por ejemplo: sistemaentorno / elemento-relación; entorno externo / entorno interno; cultura como memoria / cultura como temas; etc. Junto con ello, se insiste en que los procesos de autobservación y de heterobservación de la sociedad, en cuanto operaciones del sistema, constituyen procesos opacos para la propia sociedad. Esta opacidad operativa sólo puede ser 'superada' por la autodescripción semántica de la sociedad. Por lo mismo la denominación como cultura de tales procesos operativos es contingente a la semántica propia de nuestra contemporaneidad.

El objetivo central de esta primera parte puede entonces señalarse como el de realizar un quiebre radical en la pregunta por la cultura; quiebre que se deduce del cambio de paradigma realizado por la teoría de sistemas sociales elaborada por Luhmann. Sin embargo, aún cuando este giro implica una serie de dificultades derivadas de la aproximación a un nuevo lenguaje teórico, resulta sumamente necesario para repensar la especificidad de lo que indicamos cuando en ciencias sociales decimos 'cultura'. Pero no se trata aquí de señalar un nuevo punto cero para las ciencias sociales e intentar echar por la borda la larga suma de reflexiones que debemos a nuestros antepasados. La segunda parte de este documento, 'Cultura y Antropología' tiene como objetivo mostrar hasta qué punto es posible integrar las múltiples aportaciones que nos entregan la tradición sociológica y antropológica a este nuevo lenguaje.

Más específicamente, una vez señaladas las operaciones de autobservación y heterobservación como constitutivas de lo cultural se intenta aquí, a la luz de lo ya dicho por la antropología y la sociología, observar como estas operaciones se concretizan en la vida social. En este diálogo tienen una centralidad clave los trabajos de Durkheim, Mauss, Lévi-Strauss, e incluso de filósofos tan distintos como Renaut o Derrida para señalar algunos de los referentes de lengua francesa. También se consideran algunos de los aportes de Geertz, Sahlins, Turner, Wolf y Kuper entre los de lengua inglesa. De la misma forma la referencia a Weber es inevitable, así como también a Castoriadis o al ya mencionado Appadurai. Destaca también la influencia de algunos antropólogos y 
sociólogos españoles y latinoamericanos como Delgado, Arnold, Pintos, Morandé o Beriain.

Las tesis que se indican en esta parte, 'Cultura y Antropología', apuntan a indicar dos tipos de fenómenos sociales como característicos de las operaciones de autobservación y heterobservación de la sociedad. Para las primeras se indica un tipo particular de interacciones en las que se pone en juego el límite de lo social. La metáfora clave para pensar en tales fenómenos la tomamos de Durkheim y su concepto de 'efervescencia colectiva'. De la misma forma, se aventuran algunas hipótesis respecto a las formas específicas (experiencia mágica, profética, revolucionaria, urbana) que tales fenómenos adquirirían en distintos tipos de sociedades (segmentadas, estratificadas, funcionalmente diferenciadas). Respecto a la heterobservación de la sociedad la metáfora clave la tomamos de Castoriadis y más específicamente de aquello que indica como 'institución imaginaria de la sociedad'. Al igual que en el caso anterior las hipótesis refieren a la forma que esta institución (lo colectivo, lo superior, la nación, lo público) adquiriría en sociedades diferenciadas a partir de criterios distintos.

\section{CULTURA Y TEORIA DE SISTEMAS}

Una ciencia es cualquiera de las disciplinas en que el ignorante de la generación presente puede dar un paso más allá del punto alcanzado por el genio de la generación

anterior.

Max Gluckmann

Se debe plantear, en primer lugar, que los conceptos de autodescripción y autobservación designan operaciones reales de los sistemas sociales. Por lo tanto la discusión teórica de este documento debe comprenderse como una revisión crítica de un marco de distinciones para observar sociológicamente fenómenos reales. Las clásicas paradojas de la observación, que incluyen a las ciencias sociales en cuanto sistema observador de la sociedad, no deben conducirnos al solipsismo constructivista. Tal como señala Geertz, si bien es cierto que los escritos antropológicos son ficciones de la sociedad, en el sentido de que son algo 'hecho', algo 'formado', algo 'compuesto' por los antropólogos, ello no implica que tales ficciones sean necesariamente falsas. De hecho, insiste Geertz, "la línea que separa la cultura (marroquí) como hecho natural y la cultura (marroquí) como entidad teórica tiende a borrarse; y tanto más si esta última es presentada como una descripción" (1973: 28). Lo que se quiere investigar en este documento son mecanismos reales de autodescripción y autobservación sistémica, y en ese sentido la sociología o la antropología no estarán libres de reconocer y designar a su antojo mecanismos sociales de autobservación ni autodescripciones sociales (1). La operatividad de estos conceptos como guías para la observación sociológica requiere ante todo clarificar específicamente sus aportaciones a la reproducción de los sistemas sociales, diferenciando también sus formas de operación.

La literatura a la que tenemos acceso desarrolla el concepto de autobservación bajo dos matices que consideramos distintos. La diferencia que anotamos pasa fundamentalmente por la forma cómo se comprende el concepto de autobservación para los sistemas 
sociales en general y para el sistema de la sociedad en particular. En ese sentido parece necesario revisar ambos matices, distinguiendo con precisión las diferencias que tendría que adoptar el concepto de autobservación para el análisis específico del sistema de la sociedad. Creemos fundamental investigar sobre estas particularidades a fin de desarrollar una conceptualización que nos permita abarcar con mayor precisión la complejidad de los fenómenos de observación de la sociedad sobre sí misma. Las diferencias que observamos nos sugieren proponer una distinción, a saber, entre operaciones de autobservación y operaciones de heterobservación de la sociedad. Se podrá argumentar que la diferencia teórica que aquí se plantea refiere finalmente a un problema de matices y énfasis, e incluso se puede señalar un problema de traducción. Si este último es el caso, aunque no lo creemos así, bienvenida sea la traducción como mecanismo de variación de la teoría y bienvenida también la reflexión a la que nos invita.

\section{i. La Autobservación Sistémica.}

En el libro Sistemas Sociales, publicado en el año 1984, Luhmann trata brevemente aunque de forma muy precisa los conceptos de autobservación y autodescripción. En Teoría de la Sociedad encontramos desarrollada la teoría de la autodescripción sistémica de una forma más sistemática. Estos dos textos constituyen la base para el análisis que presentaremos sobre las posibilidades para las ciencias sociales de trabajar con estos conceptos.

Habría que comenzar señalando que la autobservación sistémica constituye un proceso social continuo, inherente a la comunicación social. A juicio de Luhmann, ella "corre paralela en todos los sistemas sociales -hasta donde es consciente y para quién, es otra pregunta- y solo tiene realidad como comunicación" (1984: 406). La formula propuesta es clara: cada comunicación es, al mismo tiempo, una autobservación.

Cada comunicación es una autobservación en la medida que en cada una de ellas se puede observar veladamente o no, "consciente o inconscientemente, temáticamente o no, su pertenencia al sistema"(1984: 406). Es importante insistir en este matiz, autobservación sistémica no implica bajo esta forma una autoilustración o una autocomprensión, sino que implica, simplemente, una operación que se establece de acuerdo a la identidad sistémica, que la pone en juego. De forma que con cada comunicación del sistema operaría, entonces, bajo su forma más rudimentaria, un procedimiento para la autobservación sistémica.

La razón de lo anterior radica en que cada operación comunicativa de un sistema se basa e implica orientar la comunicación bajo una forma delimitada de sentido. Esta orientación de la comunicación, aun cuando no sea representable por el sistema, implica el manejo de la diferencia entre autorreferencia y heterorreferencia de la comunicación, esto es, implica el manejo de la diferencia entre sistema y entorno. La distinción autorreferencia y heterorreferencia no es entonces sino la reintroducción en el sistema de la diferencia sistema entorno; reintroducción constitutiva del sistema pues le permite reaccionar al "hecho de que, a través de su operación, él mismo produce su propia forma, es decir, produce la diferencia entre sistema y entorno" (1993: 381). Esta reacción debemos entenderla fundamentalmente como la capacidad que desarrolla un sistema para adjudicar "temas al sistema de manera diferente al entorno" (1993: 381). 
La autobservación sistémica debe comprenderse entonces como un proceso basal del sistema implicado desde la definición autorreferencial de los sistemas sociales, y que se presenta en cada evento comunicacional ligado a situaciones concretas.

El concepto de autodescripción designa el mecanismo por el cual los sistemas ordenan o coordinan ese continuo de autobservaciones, o comunicaciones. Luhmann consigna sobre este punto que "la forma más simple a que recurre el sistema consiste en darse un nombre utilizando una indicación rígida invariable (y) que puede repetirse" (1993: 381), lo cual permite, entendemos, la ordenación de las continuas autobservaciones. Pero no sólo se trata de nombres que designan la diferencia sistema / entorno -sociedad tradicional / sociedad moderna, por ejemplo-, sino también de textos más complejos que describen, por ejemplo, la estructura misma del sistema -estructura de clases, campos sociales, etc.- Luhmann concluye en este punto, "llamamos a estos textos y sus nombres, autodescripciones" (1993: 382).

La construcción de autodescripciones por parte de un sistema tiene por función compensar la limitación propia de todo sistema de ser, en el plano operacional, su propia unidad. Así, en el procesamiento autopoiético de un sistema, éste se vuelve inaccesible a sí mismo, se vuelve "tan opaco como el entorno" (1993: 383). En este contexto de opacidad para sí mismo, las autodescripciones permiten orientar la reproducción del sistema por medio de una limitación de su sentido, esto es, de su horizonte de remisiones, o más concretamente, de los temas válidos e inválidos en torno a los que se reproduce la comunicación. Tal como señala Luhmann, la autodescripción opera "representando al sistema como diferencia respecto a su entorno y obteniendo según esa diferencia las informaciones y los puntos direccionales para la conducta de enlace" (1984: 167).

Estas autodescripciones sistémicas consisten fundamentalmente en "textos largos, disciplinados, y comprensibles en gran parte como algo independiente de la situación" (1984: 406). Esto es un mecanismo distinto de las constantes autobservaciones rudimentarias, ligadas a situaciones concretas, y por lo mismo capaces de generar "una superunificación, una sobrestimación de la coherencia en la observación del sistema" (1984: 406). Por lo mismo, respecto a las autodescripciones sistémicas, las preguntas ¿hasta donde es consciente? y ¿para quién? -que quedan sin respuesta en el análisis de la autobservación- sí se vuelven relevantes.

A través de las autodescripciones el sistema se vuelve consciente para sí mismo. Hasta dónde es consciente de sí mismo es algo que sólo puede señalarlo la historia del sistema, de acuerdo a la efectiva capacidad de sus autodescripciones para guiar con sentido sus procesos comunicativos. Esto en razón de que estas autodescripciones no pueden ser juzgadas bajo ningún criterio externo a sí mismas: "En todos los casos de autodescripciones de la sociedad, los criterios no se han establecidos antes o independientemente de la autodescripción misma" (1993: 385), por lo que sólo "pueden fundamentarse de manera circular" (1993: 386).

Ahora bien, el particular ordenamiento de las formas de autodescripción social en un momento determinado de la historia de un sistema recibe el nombre de semántica. Este concepto designa entonces el conjunto de autodescripciones seleccionadas evolutivamente por su capacidad de orientar eficazmente el sentido de un sistema: "Llamamos semántica a las premisas de sentido que merecen ser conservadas" (1993: 383). 


\section{ii. La Autobservación de la Sociedad.}

Así comprendidos estos conceptos no pueden simplemente extrapolarse al sistema de la sociedad. Su análisis fuerza algunas precisiones que requieren a su vez introducir distinciones teóricas que están contenidas en la obra Luhmann, pero que no hemos visto relacionadas directamente con los conceptos de autobservación y autodescripción de la sociedad (2). Antes, sin embargo, habremos de señalar las peculiares características del sistema de la sociedad, puesto que sobre ella radica nuestro interés.

El concepto de sociedad que Luhmann propone constituye un quiebre muy importante dentro de las ciencias sociales. Esto, pues al proponer como elemento constitutivo de la sociedad la comunicación, no sólo deja fuera la referencia a los seres humanos implícita en el concepto de acción, sino que también se distancia de las definiciones territoriales o regionales de la sociedad. Con ello queda establecido un tercer punto: si la sociedad no se puede caracterizar como unidad de territorio o grupo de hombres, no es posible tampoco pretender que la sociedad pueda ser observada o descrita desde fuera de sí misma (1993: 31-32). Luhmann sostiene entonces que: "la sociedad es el concepto social más amplio, incluye todo lo social y, por consiguiente, no conoce ningún entorno social. Si se agregan factores sociales, si surgen interlocutores o temas de comunicación novedosos, la sociedad crece, pues esos factores se arraigan en la sociedad, no pueden ser externalizados ni tratarse como una cosa del entorno, ya que todo lo que es comunicación es sociedad" (1984: 366).

A partir de esta definición Luhmann llega a sostener que la sociedad "es el sistema social autopoiético por excelencia. Hace comunicación y todo lo que haga comunicación es sociedad' (1984: 366). Esta es la especificidad del sistema de la sociedad, puesto que los sistemas sociales parciales sí establecen contactos con su entorno a partir de la diferencia entre heterorreferencia y autorreferencia. La sociedad, en cambio, no. La relevancia de esta peculiaridad de la sociedad radica en las consecuencias que tiene para la formación del sentido. La posición de Blauberg, que Luhmann reseña, es que "el sentido de un sistema sólo puede aclararse haciendo referencia a un sistema más amplio" (1984: 368). En el caso de la sociedad, al no poder referir a ningún entorno, solo se podría hacer referencia a su sentido a partir de su diferenciación interna, esto es, no como sistema sino, entendemos, como mundo -horizonte de remisiones - respecto al cual se diferencian los sistemas sociales. Frente a esto Luhmann señala: "preferimos suponer que la sociedad es un sistema para el que no existe un sistema que lo abarque, de manera que no es posible concebirlo desde afuera, sino solo desde la autobservación, desde la autodescripción, desde una autoilustración de sus propias operaciones" (1984: 368).

El problema al que se enfrenta en este punto la teoría de los sistemas sociales autopoiéticos es bastante complejo, puesto que plantea la pregunta por las formas en que el sistema sociedad puede autobservarse, esto es, de qué manera la sociedad puede reintroducir la diferencia sistema entorno, si a su vez no puede siquiera vislumbrar un entorno no comunicacional. Los demás sistemas sociales, señala Luhmann, sí "establecen relaciones de comunicación con su entorno" (1984: 36). Precisamente su clausura les permite desarrollar una apertura hacia el entorno, una apertura cognitiva, necesaria para construir su propia identidad y orientar su desarrollo por la constitución de la diferencia heterorreferencia / autorreferencia. Pero en el caso de la sociedad, tal apertura no sería posible puesto que, tal como señala Luhmann, su entorno no es 
comunicacional, por lo tanto no es siquiera distinguible. La solución que nos plantea Luhmann es la siguiente:

La sociedad se constituye, gracias a su autocerradura, como "un sistema en el entorno" (1984: 367), que "aunque (...) se diferencie de su entorno de una manera rutinaria, no queda por eso claro desde el inicio qué es lo que se diferencia de su entorno" (1993: 48). En ese sentido, lo que no quedaría claro es la diferencia a partir de la cual se construye 0 reflexiona la identidad de la sociedad. En esta peculiaridad radicaría "la capacidad de rendimiento particular del sistema... La sociedad sólo puede comunicar acerca del entorno (acerca de los sistemas sociales), pero solo por eso puede comunicar acerca del sí mismo" (1984: 367).

A lo que Luhmann refiere entonces es a que en la sociedad no se comunica sobre la sociedad directamente, sino a través de las comunicaciones efectuadas continuamente desde y sobre los distintos sistemas sociales diferenciados en la sociedad. Según Luhmann esta incapacidad de la sociedad para comunicar sobre sí misma directamente viene dada por la propia estructura de la comunicación, y el imperativo de la selección de una información: "Se comunica sobre algo, sólo excepcionalmente se comunica sobre la comunicación” (1984: 367).

La solución planteada por Luhmann al problema de la reintroducción de la diferencia sistema / entorno en el caso de la sociedad se basa en una doble posición del sistema sociedad. Éste sería el sistema social omniabarcador a partir del cual se diferencian los sistemas sociales, pero al mismo tiempo se constituiría como un sistema en el entorno de estos sistemas. Así, la observación de su diferencia sistema / entorno sería posible indirectamente a través de las diferencias establecidas por los sistemas sociales respecto a la sociedad.

En este punto, cobraría sentido la definición de autobservación (que anotábamos como apropiada para los sistemas parciales) como aquel rudimentario proceso continuo de distinción heterorreferencial - autorreferencial de toda comunicación. Esto pues la autobsenación se derivaría lógicamente de las paradojas de la observación, y específicamente de aquellas que indican que si bien "el observador ... es ciego para sus propias operaciones, pues no ve que no ve lo que no ve ..., está incluido en su observación (puesto que) la observación es su observación y habla de él". De esta manera, "el ciego (1 $1^{a}$ paradoja) que se observa en sus propias observaciones (2 ${ }^{a}$ paradoja) observa en realidad a otro cuando se observa a sí mismo: es él mismo y otro como observador y como observado" (Ramos-Torre 1997: 140). La observación de la sociedad resultaría entonces de lo incluido en el lado heterorreferencial de las múltiples comunicaciones que acontecen simultáneamente en la sociedad. Por lo mismo, la autobservación de la sociedad se realizaría policontextualmente (1993: 47).

La precisión de este argumento y fundamentalmente su capacidad para develar lógicas empíricamente observables lo vuelven inobjetable. Sin embargo quisiéramos señalar dos observaciones. La primera refiere a que en términos estrictos la autobservación de la sociedad, como reintroducción de la diferencia sistema-entorno, no se puede deducir o analogar a las heterobservaciones que sobre la misma realizan los sistemas sociales. Estas se tratan, mas bien, de observaciones de la sociedad a partir de su diferencia con un sistema social parcial y por lo tanto, creemos, refieren más a la estructura de diferenciación interna de la sociedad que a su estructura de diferenciación externa. Sin embargo de esto no se deduce que debamos atender la sugerencia de Blaumerg, 
reseñada por Luhmann, respecto a que no podríamos, entonces, considerar la sociedad como un sistema. Por el contrario, creemos que debe ser atendida la insistente sugerencia de Luhmann de que excepcionalmente la sociedad comunica sobre la sociedad, esto es, por lo tanto, de la posibilidad de que la sociedad reflexione directamente sobre la diferencia con su entorno externo, a pesar de que tal posibilidad no la encontremos desarrollada teóricamente en la literatura a la que tenemos acceso.

Así, respecto al concepto de autobservación de la sociedad proponemos comprenderlo como algo distinto de la operación comunicativa basada en la diferencia autorreferencia / heterorreferencia propia de toda observación. En términos estrictos, con el concepto de autobservación de la sociedad se hará referencia en lo que sigue a unos excepcionales episodios comunicativos en los que se da un tipo muy particular de observación de segundo orden, a saber, la observación de la diferencia entre sociedad y entorno. Este es un tipo de observación de segundo orden muy distinto a lo que podríamos denominar la heterobservación sobre la sociedad; que se realiza desde los sistemas sociales y que, por lo tanto, es continua y policontextual (3). Para desarrollar esta distinción habrá que introducir algunas nuevas precisiones teóricas: primero, la del concepto de observación de segundo orden, segundo, lo que Luhmann señala como las diferencias constitutivas de los sistemas sociales, y tercero, la diferencia entre entorno interno y externo de la sociedad.

\section{a. La observación de segundo orden.}

Lo que arriba denominamos como 'autobservación de la sociedad' y 'heterobservación sobre la sociedad' deben entenderse como tipos especiales de observación, observaciones de segundo orden. La observación de segundo orden se caracteriza por constituir una observación de observaciones, es decir, observaciones que observan las distinciones con las cuales un observador distingue un campo sin dejar "fuera con ello nada distinguible" (Pintos 1997: 127).

Toda observación se basa en la introducción de una distinción que busca dar cuenta de una diferencia. A través de esta distinción se señalan dos lados de los cuales toda observación indica uno por oposición al otro. Este último constituye aquello de lo cual no se comunica y encierra todo lo observado en un momento dado, pero que no es indicado. Sin embargo, en toda observación la distinción misma, el criterio bajo el cual se construye la diferencia queda, no solo fuera de lo indicado, sino fuera del campo de la observación. Por eso "la distinción es el punto ciego que en cada observación se presupone como la condición de su posibilidad: el observador es lo no observable" (Pintos 1997: 127). La observación de segundo orden se caracteriza por observar precisamente aquellos puntos ciegos a partir de los cuales el observador observa.

Se trataría, en todo caso, de observaciones de segundo orden muy distintas. La heterobservación sobre la sociedad, realizada al nivel de los sistemas sociales, se encontraría fundamentalmente orientada por la observación de las formas a partir de las cuales la sociedad se diferencia a sí misma. La distinción autorreferencia / heterorreferencia a partir de las cuales se realizan este tipo de observaciones de segundo orden permitirían señalar aquel criterio a partir de los cuales la sociedad recrea en su interior diferenciaciones sistema entorno (4).

La autobservación de la sociedad, en cambio, señalaría un tipo de observación de segundo orden directamente orientada a señalar la forma de diferenciación sistema / 
entorno de la sociedad. Como ya observamos, el mismo Luhmann señala que 'aunque (la sociedad) se diferencie de su entorno de una manera rutinaria, no queda por eso claro desde el inicio qué es lo que se diferencia de su entorno'. La autobservación de la sociedad debe entonces comprenderse como la observación de esta invisibilidad, de este punto ciego.

Así, mientras la heterobservación sobre la sociedad tendría un valor referencial (la diferencia autorreferencia / heterorreferencia), la autobservación tendría sobre todo un valor reflexivo (reintroducción de la diferencia sistema / entorno) (5).

\section{b. La distinción sistema / estructura.}

Los sistemas sociales se constituyen sobre dos diferencias constitutivas, a saber, la diferencia sistema / entorno y la diferencia elemento / relación. Luhmann señala claramente que "hay que distinguir la diferencia entre sistema y entorno mediante una segunda diferencia constitutiva: la que existe entre elemento y relaciór' (1984: 44) (6). Ambas dimensiones son claves para el análisis de los procesamientos de información sistémicas.

La diferencia sistema entorno es una diferencia a partir de la cual se constituyen los sistemas. Así lo sostiene Luhmann en su ya clásica definición de sistema como su diferencia con el entorno. El entorno, incluido en esta diferencia, "es mas bien una condición previa de la identidad del sistema" (1984: 173). La diferencia sistema entorno, entonces, es constitutiva del sistema y define su identidad. Ahora bien, Luhmann señala que esta diferencia no es ontológica, sino resultado de la aplicación de distinciones en la observación.

La diferencia elemento relación en cambio no indica tanto sobre la identidad del sistema como sobre la forma en que éste estructura su complejidad. Los elementos constituyen la unidad última de los sistemas sociales, pero no están, como podría suponerse, dados ónticamente. Un elemento (cada comunicación) es constituido como tal sistémicamente en la medida que es tomado como elemento para la relacionalidad (comunicativa). Este ámbito relacional de los elementos constituidos en el sistema constituye precisamente un segundo ámbito de constitución de los sistemas sociales. Sin embargo señala Luhmann "los sistemas no son simplemente relaciones (en plural) entre elementos. En alguna parte tienen que estar reglamentada la conexión de las relaciones" (1984: 46). Aquí entra en juego el concepto de estructura que Luhmann define como "la limitación de las relaciones permitidas en el sistema" (1984: 259). Este condicionamiento permite dar sentido al sucesivo acontecer de comunicaciones (elementos) en el sistema, aportando así una direccionalidad a la reproducción autopoiética de la sociedad.

La clave del análisis que planteamos radica en la posibilidad de distinguir entre autobservación y heterobservación de la sociedad como formas de observación de segundo orden orientadas diferenciadamente sobre la diferencia sistema / entorno y sobre la diferencia elemento / relación. Así mientras el análisis de la autobservación de la sociedad apunta a la observación de como se distingue la identidad de la sociedad, el análisis de las heterobservaciones sobre la sociedad quedaría acotado a la observación de la orientación estructural de la reproducción autopoiética. 


\section{c. Los entornos de la sociedad.}

Estos planteamientos requieren ser precisados a partir de la diferencia establecida por Luhmann sobre la observación del entorno de la sociedad: la diferencia entorno externo / entorno interno.

En el contexto del análisis de las formas de subdiferenciación sistémica Luhmann acuña el concepto de entorno interno. La diferenciación sistémica refiere a la formación de sistemas dentro de un sistema, y refiere por tanto a sistemas interaccionales complejos, a sistemas organizacionales, a sistemas funcionales y también, aunque de forma especial, a la sociedad. En todos estos casos "el sistema global adquiere la función de 'entorno interno' para los sistemas parciales, el cual, sin embargo, es específico para cada uno de ellos" (1984: 42). Esto implica que la identidad de los sistemas parciales de un sistema global se constituirá por una diferencia sistema entorno, con la peculiaridad que la selección del entorno por el sistema parcial tendrá como horizonte de posibilidades la complejidad del sistema global.

Esta diferenciación, que provoca forzosamente un aumento de complejidad en el sistema global, dada la introducción de una nueva diferencia, tiene como origen, a su vez, la necesidad de reducir a complejidad de la información procesada por el sistema. Cada sistema parcial, señala Luhmann, por el hecho de diferenciarse respecto al sistema global reconstruye a este último en su interior como medio de orientación de su reproducción comunicativa.

El concepto de entorno externo viene a señalar por el contrario el entorno respecto al cual se constituiría un sistema global, por Ej. un sistema organizacional o un sistema funcionalmente diferenciado. En un sistema como los mencionados, su entorno externo resultaría de una selección particular realizada por el sistema de un horizonte total de remisiones, es decir, lo que el sistema selecciona como su entorno corresponde a una parte del 'mundo'.

Ahora bien, esta distinción cobra una particular connotación cuando se aplica al sistema de la sociedad intentando señalar la forma en que esta procesaría su entorno. En primer lugar cabe señalar que a juicio de Luhmann, la sociedad constituye el sistema social omniabarcador y, por lo tanto, el sistema autopoiético por antonomasia a partir del cual se diferencian los sistemas sociales. Sin embargo, Luhmann también señala, ya lo hemos citado, que la sociedad se posiciona, al mismo tiempo, como un sistema en el entorno de los sistemas sociales parciales. Así, en la medida que la sociedad es capaz de referir a los sistemas sociales parciales como su entorno resuelve en parte las paradojas derivadas de su unidad tomando una parte de sí misma como su entorno. En esta operación de distinción entre sistema y entorno en la propia sociedad el entorno al que refiere la sociedad constituye por definición un entorno interno. Así por ejemplo Luhmann sostiene que en el caso de la sociedad moderna "se puede definir lo público ... como el entorno interno de la sociedad de todos los subsistemas sociales. Por consiguiente el entorno interno de todas las interacciones y de todas las organizaciones; de los sistemas de funciones y de los movimientos sociales" (Luhmann 1995).

El entorno interno de la sociedad, a partir de la cual ella misma se diferencia, constituye entonces el ámbito privilegiado desde donde la sociedad, manifiesta o veladamente, representa para sí su estructura de diferenciación interna. Como ya lo hemos señalado, se trataría de una observación de la sociedad sobre sí misma derivada de la forma en que 
los subsistemas parciales se diferencian en su interior e indicada por el lado heterorreferencial de la distinción autorreferencia-heterorreferencia. El entorno interno de la sociedad moderna, según Luhmann lo público, indicaría aquello respecto a lo cual la política, la economía o las universidades se diferencian; en el caso de las sociedades segmentadas, podríamos aventurar que aquello respecto a lo cual se diferencian los linajes o las familias es lo colectivo. De esta forma, a través de la observación de segundo orden que realiza la sociedad por diferenciación respecto a su entorno interno lo que se observa es la forma de su diferenciación interna, su orientación estructural.

En segundo lugar, dado el carácter omniabarcador del sistema de la sociedad, su entorno externo constituye necesariamente un entorno no comunicacional. Ahora bien, dado que lo que se procesa en sociedad son comunicaciones, el carácter no comunicacional de su entorno externo vuelve imposible su observación. Por lo mismo, la constitución del sistema de la sociedad a partir de la diferencia sistema entorno deviene problemática puesto que no es posible reintroducir directamente la diferencia sistema entorno en el sistema. Todo procesamiento del entorno en el sistema deviene por lo tanto de una afirmación ontológica respecto al carácter del entorno de la sociedad.

Para el ámbito sistémico la ontologización de las comunicaciones operaría como un mecanismo orientado a asegurar la aceptación de una selección de sentido de alter por ego. Señala Luhmann, sin embargo, que a lo largo del proceso evolutivo de la sociedad tales ontologizaciones "son sustituid(a)s, más o menos, por los códigos ampliados de medios de comunicación simbólicamente generalizados" (1984: 149). Un ejemplo de ello sería, por ejemplo, el reciente quiebre en la teoría económica basado en el reemplazo de la distinción necesidad / satisfacción por el de demanda / oferta.

Sin embargo, para el caso del sistema de la sociedad podemos observar que tales formas de ontologización se encuentran lejos de ser sustituidas. Si bien es cierto que los clásicos entornos externos a partir de los cuales se observaba la sociedad a sí misma, como la Naturaleza, Dios o la Razón, alcanzan en la sociedad moderna un bajo rendimiento, es posible distinguir un privilegiado ascenso de la figura del Individuo como entorno externo a partir del cual la sociedad moderna se observa a sí misma.

Entorno interno y entorno externo de la sociedad refieren por tanto a horizontes a partir de los cuales la sociedad se autobserva de carácter sumamente distinto. Mientras el entorno interno de la sociedad haría referencia a la forma en que la sociedad en cuanto sistema global se diferencia estructuralmente, el entorno externo haría referencia a un entorno no comunicacional a partir del cual la sociedad observa el límite a partir del cual adquiere una identidad. Ambos entornos han de ser reconstruidos en el interior de la misma sociedad, pero mientras el entorno interno asumiría la forma de un ámbito a partir del cual se realiza la diferenciación interna, como por ejemplo lo público o lo colectivo, el entorno externo sería reconstruido socialmente en referencia a ámbitos ontológicos a partir de los cuales se observaría lo social, como por ejemplo la Naturaleza, Dios o el Individuo. Esta distinción teórica debemos situarla en continuidad con la distinción que venimos trabajando entre autobservación y heterobservación de la sociedad. Mientras la autobservación refeririría a la reintroducción del entorno externo de la sociedad, no comunicacional, su heterobservación lo haría a la observación de su diferenciación interna respecto a su entorno interno. 


\section{iii. La Cultura en la Sociedad.}

El concepto de cultura en la teoría luhmanniana tiene aparentemente una posición marginal. Esto pues en sus análisis sobre los sistemas sociales apenas es posible encontrar alguna referencia al concepto de cultura. En nuestra opinión, tal situación se debe fundamentalmente al intento explícito del autor por distanciarse de las posiciones clásicas de teoría social que intentan explicar a través de este concepto la conformación de lo social como unidad simbólico-normativa. En ese sentido, la teoría de sistemas rechaza de plano la posibilidad de establecer una distinción teórica entre sociedad y cultura como ámbitos independientes, o más bien de la cultura como una región de lo social con status ontológico propio.

Una de las críticas desarrolladas por Luhmann, a la luz de la teoría de sistemas, refiere al concepto más 'clásico' de cultura. Para tal crítica, Luhmann refiere directamente a la concepción parsoniana del sistema de la acción social, previamente denominado por el mismo autor como 'acto unitario'; concepción que intenta integrar las aportaciones teóricas de Durkheim y Weber (7). Respecto a la normatividad implícita en la acción social Parsons sostiene que "la eliminación del aspecto normativo elimina completamente el concepto mismo de acción y lleva a la postura positivista radical" (citado por Cousiño 1990: 40). A juicio de Luhmann, Parsons presupone la transmisión de cultura entendida como algo inmanente, como un sistema simbólico compartido que permite resolver la situación de doble contingencia. Luhmann cita en este contexto a Parsons, quien afirma que "tal sistema (un sistema simbólico compartido), con su mutualidad de orientación normativa, es lógicamente la forma más elemental de cultura... Sin cultura ni las personalidades humanas ni los sistemas sociales serían posibles" (Parsons citado por Luhmann 1984: 130).

La teoría de sistemas permite elaborar una severa crítica a estas posiciones. El problema teórico de la doble contingencia no requiere a juicio de Luhmann la referencia a la cultura, entendida como orientaciones normativas compartidas por alter y ego. Tales teorizaciones sobre la posibilidad de un consenso social anterior respecto a aspectos normativos no atenderían correctamente a las características del problema de la doble contingencia. A juicio de Luhmann el concepto clave en esta situación es el de expectativas y el de expectativas de expectativas, y esto porque el mismo surgimiento del problema de la doble contingencia echaría a andar un proceso de solución del problema, proceso que no es otro que el de la comunicación. La teoría de sistemas nos lleva entonces a dar vuelta completamente la perspectiva parsoniana: la comunicación no necesita de un consenso previo, por el contrario, ella misma emerge como proyecto inacabado e inacabable de resolución al problema de la doble contingencia.

Así, las expectativas de alter sobre las expectativas de ego, que a su vez se basan en sus expectativas sobre alter, conforman un círculo autorreferencial irreducible tanto a alter como a ego. Lo que se genera así es algo nuevo, emergente, en donde cada elemento comunicativo depende del condicionamiento impuesto por el otro. Este proceso, continuado recursivamente, permite finalmente la formación de estructuras, que no se pueden observar sino como "la limitación de las posibilidades permitidas en el sistema" (1984: 259). Esto es, la formación recursiva de condicionantes comunicativas autoseleccionadas por la comunicación.

La siguiente crítica que reseñamos la desarrolla Luhmann para el tratamiento demasiado 'general' del concepto de cultura en las ciencias sociales. Preferimos citar aquí al autor en 
extenso: "Se ha expandido tanto el espectro del concepto que bien puede considerarse ya demasiado amplio. Abarca desde los fundamentos simbólicos de la acción (Parsons) hasta la totalidad de los artefactos humanos. Incluye las máquinas electrónicas hasta los tatuajes en el cuerpo humano, altas culturas y culturas cotidianas; cultura de las tribus arcaicas y cultura de las sociedades modernas. Y si además se le añade el concepto de cultura biológico ..., entonces ya casi no se pueden establecer límites de lo social” (1999). La amplitud que este concepto tendría en las ciencias sociales entraría entonces en contradicción con la mínima especificidad requerida para la operatividad de los conceptos científicos. Resulta entonces necesario para distinguir algo como cultura distinguir también algo como no cultura, y en ese sentido se debería renunciar a la posibilidad de designar con tal concepto una región ontológica del mundo que lo abarca todo.

Frente a tales problemáticas conceptualizaciones del concepto de cultura, es posible reconocer, en la bibliografía estudiada, al menos dos aproximaciones explícitas de Luhmann a la idea de cultura. Si bien se trata, en ambos casos, de referencias periféricas al grueso de la teoría de sistemas sociales autopoiéticos, se desprenden directamente de la teoría, y alcanzan una asombrosa congruencia con lo que hasta aquí se ha expuesto.

\section{a. La cultura como temas.}

En Sistemas Sociales (1984) encontramos una aproximación muy precisa sobre el concepto de cultura construida en torno al concepto de 'temas de la comunicación'. Los sistemas sociales en su constitución como diferencia sistema entorno establecen, en la práctica, una diferencia entre temas de atribuibles a sí mismo y al entorno. La comunicación requiere así la especialización de islas temáticas para devenir un proceso continuo.

La distinción que Luhmann hace entre cultura y semántica se estructura en torno al problema de los temas. A juicio de Luhmann, para la reproducción de los sistemas, es necesaria la existencia de un conjunto de temas que estén listos para entrar rápidamente en los procesos comunicativos. Ese conjunto de temas es lo designado entonces como cultura. De esta manera, "la cultura no es un contenido de sentido necesariamente normativo, pero sí una determinación de sentido (reducción) que hace posible distinguir ... entre aportaciones adecuadas e inadecuadas, o bien entre un uso correcto o incorrecto de los temas" (1984: 161). A lo que refiere Luhmann bajo este concepto de cultura no es sino a la constitución temática de los sistemas sociales que facilitaría la relación entre sistemas sociales e interacción.

A partir de esta aproximación sobre el concepto de cultura podemos encontrar una clara simetría entre lo aquí postulado por Luhmann y el concepto de heterobservación de la sociedad que venimos proponiendo. La cultura de la sociedad quedaría delimitada por las múltiples diferencias temáticas a partir de las cuales se diferencian los sistemas sociales de la sociedad. La heterobservación de la sociedad, como observación de segundo orden estructurada a partir de las diferencias entre sistemas parciales y entorno interno de la sociedad, quedaría así entonces directamente ligada a lo que podemos denominar cultura de la sociedad. 


\section{b. La cultura como memoria.}

En el artículo 'La cultura como concepto histórico' (1999) Luhmann redefine el concepto de cultura a partir del concepto de memoria de los sistemas sociales. A juicio de Luhmann, la cultura debe ser comprendida como un tipo muy especial de observación de segundo orden realizada por los sistemas sociales, caracterizada por estar orientada a la comparación desde una perspectiva independiente respecto a "relaciones de preeminencia y a los distintos valores que están en boca de todos, y que debe ser compatible con diversos tipos de prioridades" (1999). Se trata así de una observación de segundo orden que se realiza desde una posición no jerárquica pero universal. En ese sentido, sostiene Luhmann se trata de una observación similar a la de la memoria. En Sistemas Sociales (1984: 84 nota 22), Luhmann sostiene que un sistema sólo se reproduce en presente y que para ello no necesita memoria. La memoria solo existe para un observador. Así, la memoria de los sistemas sociales debe entenderse no como una masa fija de signos que se conserva sino como la capacidad de organización selectiva para comunicar en el presente sobre acontecimientos (8).

Tal organización selectiva sólo es posible a través de la distinción olvidar / recordar, donde el recuerdo funge como un tipo de comunicación excepcional basada en la represión de la orientación estructural de la comunicación hacia el olvido. Tales excepciones se encontrarían motivadas por razones internas o externas del sistema de condensar identidades, identidad que no refiere sino a la diferencia sistema entorno. La memoria permitiría al sistema reaccionar y reproducir la diferencia sistema entorno en situaciones excepcionales en la que el sistema no puede diferenciar entre sistema y entorno. Así, "cuando ningún esquema del sistema produce efecto para poder elegir los datos y ordenarlos, la memoria enlaza el pasado y el futuro, ya que la memoria no se da cuenta de que el pasado es obsoleto y permite que el fenómeno aparezca como conocido, como confiable" (1999). La cultura del sistema queda entonces demarcada por estas orientaciones hacia el futuro, permitiendo compensar la minimización temporal de la actualidad operativa del sistema.

Esta conceptualización nos permite precisar lo que sosteníamos en el apartado respecto al concepto de autobservación de la sociedad. La autobservación de la sociedad, entendida como episodio comunicativo (interacción) excepcional en el cual se comunica sobre la propia comunicación, constituiría un espacio privilegiado para la emergencia de la memoria de la sociedad. Ese tipo de episodios constituirían entonces espacios donde la sociedad se observa a sí misma como unidad entre pasado y futuro a partir de una identidad fija. La paradojización de la comunicación encontraría en la memoria del sistema la posibilidad de asimetrizar la comunicación a partir de una diferencia, distinguiendo así por ejemplo entre Naturaleza, Dios o Individuo y Sociedad. Lo que identificamos así como autobservación de la sociedad también quedaría directamente ligada a cualquier conceptualización de un concepto de cultura de la sociedad.

\section{c. La cultura en la sociedad.}

El concepto de cultura, que integra lo que en este documento hemos definido como autobservación y heterobservación de la sociedad, debe además construirse por distinción a la semántica de la sociedad. Luhmann señala que la semántica de la sociedad se distinguiría de la cultura por su referencia a los temas almacenados específicamente para fines comunicativos. Como observamos al comienzo de este documento, la semántica refiere a aquellas distinciones temáticas que permiten la reproducción evolutiva 
de los sistemas sociales, y en ese sentido, la semántica de la sociedad debemos comprenderla más como la descripción que la sociedad realiza de los códigos simbólicos a partir de los cuales se orientan los distintos sistemas sociales, y no tanto en referencia a estos procesos de autobservación y heterobservación de la sociedad.

Autobservación y heterobservación de la sociedad constituirían entonces operaciones basales de los sistemas sociales y por lo tanto opacas para la misma sociedad. Pero mientras la heterobservación constituye un proceso continuo implicado en cada episodio comunicativo, la autobservación de la sociedad constituye un episodio excepcional relacionado con la paradojización de la sociedad. De ambas operaciones el sistema puede 'informarse' por medio de su autodescripción, y en ese sentido de la elaboración de una particular semántica. La denominación de ambas operaciones de la sociedad como cultura se encuentra de hecho determinada únicamente por la semántica propia de nuestros tiempos. A lo que nos referimos es a que 'cultura' aparece como el mejor nombre para designar esos procesos de acuerdo con la semántica contemporánea.

En su artículo 'La cultura como concepto histórico' Luhmann reseña precisamente el surgimiento moderno del concepto de cultura. Su origen lo rastrea Luhmann en el siglo XVIII asociado con una perspectiva comparativa aplicada a distintos temas, regiones, tiempos históricos, etc. El surgimiento entonces de una comunicación sobre la cultura se encuentra asociado al surgimiento de una sociedad mundo que permite sobrepasar las diferencias espaciales y temporales para esta observación de segundo orden. Esta semántica de la sociedad moderna, estructurada en torno al concepto de cultura, y que adquiere el carácter no jerárquico y mas bien cambiante que comentábamos anteriormente, enseñaría precisamente un nuevo orden en la observación de la sociedad, un nuevo orden de su memoria y un nuevo orden de sus temas. La cultura como semántica propiamente moderna en cuanto se libera de un sentido de lo absoluto se correspondería con el nuevo tipo de diferenciación funcional de la sociedad y, al mismo tiempo, permitiría como ninguna otra la irrupción del yo individual y de su poder de convicción (Luhmann 1999).

En definitiva. La cultura, lejos de constituir un aspecto marginal en la obra de Luhmann, aparece mas bien como un eje central del análisis. Sin embargo, consideramos que el tratamiento de este concepto requiere una sistematización como la propuesta a partir de introducir una nueva distinción, a saber, la distinción entre autobservación de la sociedad y heterobservación de la sociedad. Ambas operaciones deben diferenciarse pero al mismo tiempo integrarse en un concepto de cultura de la sociedad que pretenda dar cuenta de la complejidad de la misma. De la misma manera, la distinción entre cultura y semántica permite vislumbrar de qué forma estas observaciones que la sociedad realiza sobre sí misma pierden opacidad y se estructuran como nombres y textos. 


\title{
II. CULTURA Y ANTROPOLOGÍA
}

\author{
No sé cuántas veces he deseado no haber oído nunca \\ la maldita palabra.
}

Raymond Williams

\begin{abstract}
En Cultura: La versión de los antropólogos (1999) Adam Kuper elabora una juiciosa y documentada crítica a la antropología norteamericana, señalando las dificultades que supone reducir la interpretación y explicación de lo social únicamente a la cultura. A su juicio, la precisión que habría tenido el concepto de cultura en la tradición antropológica inglesa, por ejemplo, actualmente se encontraría disuelta. Actualmente se señala todo como cultura, y por lo mismo "deja de ser algo que se tiene que interpretar, describir, tal vez hasta explicar, para convertirse en una fuente de explicaciones por sí misma' (1999: 13).
\end{abstract}

El camino analítico recorrido por Kuper para comprender la génesis de tal centralidad de la cultura en la antropología norteamericana vuelve sobre algunos momentos clave que no está demás recordar. En el origen se encontraría Alemania. A través de ella Kuper refiere a la disputa filosófica entre llustración y Romanticismo, entre una tradición universalista y otra nacionalista, simbolizada por una oposición a Francia. La idea de cultura y la elevación de la misma a un lugar central de la sociedad sólo pueden comprenderse en relación con tal disputa. La Kulture encontraría sus orígenes en el Romanticismo alemán, y sería elaborada conceptualmente para señalar aquel carácter inmutable de un pueblo (Volkgeist) y como constitutiva de todas sus expresiones: lengua, arte, política, etc. Las ciencias sociales alemanas, su humanismo más bien, se encontraría entonces marcado por tal guía de observación. Para Kuper, la cuestión es entonces explicar cómo resulta posible el viaje de tal concepto desde la Europa profunda hacia la nueva América y qué transformaciones sufre en tan largo camino.

La clave se encontraría en la trayectoria intelectual de quizás los dos científicos sociales más influyentes del siglo XX norteamericano: Franz Boas y Talcott Parsons. El primero, de origen alemán, habría insistido en la primacía de lo cultural. Contra el determinismo de Morgan, "la tesis boasiana fundamental defendía que era la cultura la que nos hacía como somos, no la biología" (Kuper 1999: 32). Tal como señala Marshall Sahlins (1975: 72), en el pensamiento de Boas la construcción humana de la experiencia, esto es, lo social, emerge del nivel psicológico al cultural, desde el esquema conceptual a la costumbre. Para Boas, la cultura es constituyente entonces de la experiencia humana, en la medida que "al menos implícitamente, considera los fenómenos culturales en función de una imposición de un significado convencional al flujo de la experiencia'" (Stocking citado por Sahlins 1975: 73). Kuper señala que la relevancia de Boas radica en que habría sido el que introdujo este enfoque en la antropología norteamericana en gran medida dominada por el evolucionismo de Morgan.

El paso definitivo para la formación de una antropología cultural habría estado posibilitado por la influencia de Talcott Parsons sobre el mundo académico norteamericano. Durante los años 60 Parsons se sumerge en la elaboración de un proyecto verdaderamente científico para las ciencias sociales. Consecuentemente con las dimensiones a partir de las cuales comprendía la acción social, a saber, organismo, sistema psíquico, sistema 
social y sistema cultural -formulación posteriormente desarrollada como el esquema AGIL-, Parsons señalará que la constitución de la sociología y la antropología en disciplinas científicas requeriría necesariamente la especialización de la primera en lo referido a la 'sociedad', esto es, el "sistema específicamente relacional de interacciones entre individuos y colectivos" y la especialización de la segunda en lo relativo a la 'cultura', "restringiendo su referencia a los contenidos y patrones de valores ideas y otros sistemas significativamente simbólicos" (Parsons citado por Kuper 1999: 88). A juicio de Kuper esta delimitación de lo cultural habría marcado fuertemente, fundamentalmente a través de Kroeber y Kluckhohn, a los líderes de la siguiente generación de antropólogos: Geertz, Sahlins y Schneider. A partir de las obras de estos antropólogos "se continúa asumiendo que la gente vive en un mundo de símbolos. Las ideas, quizás inconscientemente, dirigen a los actores y configuran la historia. En breve, la corriente central de la antropología cultural americana está todavía en manos de un idealismo omnipresente" (1999: 38). Más allá de si se considera la crítica de Kuper como adecuada o correspondiente a los desarrollos de la antropología norteamericana, a la hora de estudiar la conexión entre la antropología y el concepto de cultura desarrollado en el apartado anterior, resulta necesario tener presentes los peligros señalados por Kuper.

De lo que se trata entonces es de señalar la especificidad del concepto de cultura que venimos proponiendo, a fin de constituirlo en una herramienta útil para el estudio antropológico. Habrá, por tanto, que señalar claramente sus límites a fin de demostrar que a través de él no se refiere a 'todo' lo social. Sus limitaciones pueden ser encuadradas en dos ámbitos. Por una parte, refiere a unas operaciones 'reales' de la sociedad. La cultura entendida como la autobservación y la heterobservación de la sociedad es algo que sucede socialmente, que se constituye como acontecimiento, como episodio comunicativo. Para hablar en los términos de Geertz habría que señalar que la cultura no es tanto un conjunto de textos que están ahí para ser leídos, sino el conjunto de lecturas de unos determinados textos. Por otra parte, se apunta a indicar que no todos los episodios comunicativos que constituyen lo social son parte de la cultura. La excepcionalidad de los procesos de autobservación de la sociedad es un claro ejemplo de esto, pues, como ya se ha dicho, mientras la comunicación permite la comunicación no es necesario comunicar sobre la diferencia entre comunicación y no comunicación. Al mismo tiempo, si bien la heterobservación de la sociedad es un proceso continuo, ligado directamente a cada situación comunicativa, no está directamente referida en estos episodios comunicativos. Constituye lo velado en tales operaciones y que solo tiene lugar en la medida que los sistemas parciales reflexionan sobre su propia identidad, esto es, sobre su diferencia con el entorno (la sociedad).

Las preguntas que quedan abiertas, y a las que se intenta ofrecer un camino de respuesta en esta parte, refieren a las formas sociales observables que asumen estas operaciones de autobservación y heterobservación de la sociedad. En ese sentido, se intenta investigar dos cuestiones: a. Cuales son los ámbitos comunicativos privilegiados en los cuales emerge la cultura de la sociedad, y b. Qué pautas históricas se pueden observar respecto a la forma de la cultura.

\section{i. Autobservación e Interacción}

En primer lugar deberíamos intentar definir con claridad el problema que delimitaría la operación de la autobservación de la sociedad. El resultado lógico privilegiado de la reintroducción de una diferencia en un lado de la misma radica la ganancia de identidad 
derivada de la posibilidad de observar la distinción con que se construye la diferencia. Los mecanismos de reintroducción de la diferencia de un sistema con su entorno específico son por lo mismo mecanismos de observación de segundo orden aplicados por un observador a sí mismo, no a otro. La autobservación, entonces, tiene como principal ganancia abrir la posibilidad de condensar la propia identidad sistémica. Sin ella no habría autopoiesis posible, ni por tanto sistema, puesto que no sería posible distinguir el sistema del entorno. Y esto es así porque los sistemas parciales requieren establecer contactos funcionales con su entorno, seleccionar temas, etc.

Ahora bien, la hipótesis que planteamos es que en el caso de la sociedad la reintroducción de su diferencia con el entorno es igualmente necesaria. Sin embargo, creemos que esta reintroducción acontece bajo formas especiales que atienden al carácter especial del sistema de la sociedad, a saber, su totalidad y la imposibilidad de establecer un contacto funcional con su entorno.

En primer lugar, la reflexión societal sobre su entorno no constituiría un problema específico al que responda un sistema funcionalmente diferenciado, sino un problema global. Es decir, se trata de una problemática no reductible a las racionalidades específicas de cada sistema y que por lo mismo su tratamiento desde estas racionalidades parciales (económica, política, religiosa, etc.) sólo amplifican el problema. Esto pues la forma como se construye la identidad de los sistemas parciales de la sociedad es por referencia a un entorno comunicativo, observable, a saber, la sociedad.

Segundo. La reflexión sobre la identidad de la sociedad implicada en estos procesos de autobservación no constituye un proceso continuo implicado en cada comunicación. Por el contrario lo que se señala a través de este concepto es un tipo especial de comunicaciones que comunican acerca de la diferencia entre comunicación / no comunicación. Así pues, no nos referimos a la comunicación en general, porque "solo excepcionalmente se comunica sobre la comunicación" (Luhmann 1984: 367). Si, como señala Luhmann, la sociedad como sistema no es un sistema autosuficiente para comunicar, y por lo tanto, las comunicaciones son sobre algo; entonces la comunicación sobre la identidad de la sociedad, esto es, sobre la diferencia entre comunicación y no comunicación, constituiría entonces el tipo de comunicación propio de la sociedad a partir de la cual se identifica a sí misma.

Tercero. De esta manera podemos sugerir que la excepcionalidad de este tipo de comunicación se actualiza para resolver el problema de la identificación de un entorno no comunicacional. En ese sentido, como resulta lógico, mientras la comunicación permite la comunicación no sería necesario comunicar sobre la comunicación, pero podemos pensar que esto no siempre acontece de esta manera. Creemos que sería posible reconocer momentos excepcionales en la reproducción autopoiética de la sociedad en los que, en la medida que resulta imposible observar la diferencia constitutiva de la comunicación, se produce una paradojización del sistema: 'la unidad de la comunicación es su diferencia con la no comunicación', o más simplemente, 'la comunicación no es comunicación'.

Cuarto. Como señalábamos tal paradojización de la sociedad (de la comunicación) constituiría un problema global y excepcional. Sin embargo tales paradojas deben administrarse, resolverse 'creativamente' a fin de no afectar la capacidad de anexión de las comunicaciones, excepcionalmente bloqueada. En sistemas autorreferentes las paradojas sólo pueden 'solucionarse' "ya sea gracias a un trabajo hábil de ocultación, ya en razón de la temporalización y asimetrización que la autopoiesis comporta, ya, por 
último, en el marco de una lógica no-tradicional que está por construir" (Ramos-Torre 1997: 143).

Nuestra investigación apunta a señalar este problema y a localizar el ámbito privilegiado desde donde estas paradojas de la sociedad se resolverían. La hipótesis que proponemos toma un tipo particular de interacciones como el espacio al cual la sociedad recurre para encontrar soluciones creativas a su paradoja primera, la de su propia unidad. Esto no significa, sin embargo, que a partir del análisis de lo anterior se pueda reconocer una identidad fija de la sociedad como unidad. Por el contrario, centrar la atención en el ámbito interaccional permite comprender que se tratará siempre de una resolución situacional de la paradoja, esto es, la emergencia de múltiples soluciones contextualizadas por una historia, por una región, y por aquellos presentes en la interacción.

Los sistemas interaccionales no están por supuesto orientados a la resolución del problema que señalamos como la paradojización de la sociedad. Por el contrario, es a través de ellos que se realiza en gran medida la comunicación de la sociedad. En ese sentido, su autopoiesis se basaría en la indexicalidad de sus comunicaciones. Los sistemas interaccionales devendrían sistemas bastante complejos dada su polivalencia, esto es, su capacidad para acoplarse a códigos comunicacionales tan diversos como amor/no amor; poder/no poder, nosotros/otros, etc (Arnold \& Robles, 2000), haciendo posible entonces la reproducción comunicativa de los distintos sistemas parciales de la sociedad. Sin embargo, habría que recordar aquello que señala Manuel Delgado a propósito de Victor Turner: "es como si existieran dos modelos distintos de interacción humana. Uno de ellos presentaría la sociedad como un orden estructurado, diferenciado, jerarquizado, estratificado, etc... El segundo, en cambio, aparece en el momento liminal y representa un punto neutro de lo social, ..., sociedad sin estructurar, recién nacida, pura y no deteriorada por la acción humana o del tiempo" (Delgado 1999: 115-116).

Intentar señalar un cierto tipo de sistemas interaccionales como ámbito privilegiado para la autobservación de la sociedad, debe a nuestro juicio evitar una analogía que de poco nos serviría para el problema específico que aquí tratamos. Se trataría de la identificación de un tipo de interacción análoga a lo que Marcel Mauss señaló como fenómeno social total, esto es, un tipo de interacción bajo la cual se integren los aspectos discontinuos (sistemas diferenciados) de la sociedad. Debemos evitar tal analogía pues en ella no se trataría de la representación de la diferencia comunicación / no comunicación, sino por el contrario de la observación simultanea de los límites a partir de los cuales se diferencian los sistemas parciales de la sociedad. En ese sentido, tales fenómenos designados por Mauss se aproximan mucho más a lo que hemos denominado aquí como entorno interno de la sociedad; lo público, lo colectivo, por poner algunos ejemplos ya mencionados a propósito de la heterobservación de la sociedad.

El giro que debemos realizar apunta en una dirección estrictamente contraria. Así nuestro objetivo sería la identificación de un tipo de interacciones en las cuales la comunicación se vuelve reflexiva, rozando, por así decir, la no comunicación. Nos acercamos de esta forma a lo que Emile Durkheim ha señalado bajo la metáfora de efervescencia colectiva. En el análisis de Manuel Delgado sobre este concepto de Durkheim se le señala como aquellas actuaciones a-sociales indiferentes a las normas establecidas, no contrarias, sino más bien al margen de lo social. Se trataría de unos estados "de excepcionalidad en el que la sociedad exist(e) en tanto que ente vivo, pero mostrándose como fuera de si (Delgado 1999: 90). Entre otras metáforas que Delgado utiliza para caracterizar estas 
situaciones 'a-sociales' está su caracterización como una 'puesta entre paréntesis' o 'en suspenso' de lo social orgánico y también como de estados de 'liminalidad' y de 'espacios intersticiales'. De la misma manera se señalan estos estados excepcionales de no sociedad como el fundamento mismo de lo social. En términos estrictos, se trataría más bien de sistemas interaccionales especiales orientados por un código comunicativo reflexivo, a saber, comunicación / no comunicación.

Esta dirección analítica es la que buscamos desarrollar a través de un tipo de sistemas interaccionales excepcionales a través de los cuales la sociedad observaría la diferencia que la constituye. Estos sistemas permitirían una representación de la unidad de lo social limitada a los contextos de la interacción. Tales resoluciones a las paradojas de la unidad de la sociedad tendrían valor sólo como episodios comunicacionales y no constituirían fuentes para una identidad global de la sociedad. Se trataría, insistimos, de resoluciones creativas de esa unidad limitadas contextualmente por la interacción. Por lo mismo, la autobservación de la sociedad constituye un episodio excepcional en la reproducción autopoiética de la sociedad, pero al mismo tiempo con resultados no necesariamente idénticos, pues dependería de los contextos y límites de la interacción. Así, mientras la observación de la sociedad realizada por el subsistema sociológico mediada por el programa teórico de la teoría de sistema autopoiéticos nos enseña la unidad operativa de la sociedad mundial, la autobservación de la sociedad como diferencia sistema entorno antes que señalar tal unidad operativa se dirigirá a señalar la unidad de la sociedad acotada al contexto de la interacción. Por lo mismo, a través de estas autobservaciones será posible reconocer o representar la diferencia sociedad-no sociedad a múltiples niveles como sociedad local, regional, nacional, etc.

La pregunta por las formas históricas cómo se concretan y lo qué implican estas operaciones de autobservación puede ser de extrema utilidad a la hora de transformar estas conceptualizaciones teóricas en herramientas útiles para la antropología. Luhmann señala en alguna parte al ensayo de Durkheim y Mauss De ciertas formas primitivas de clasificación (1901) como modelo de lo que debería constituir la investigación sobre las formas de autobservación de la sociedad. El papel clave de esta obra, así como las de otras dos escritas por Mauss, Naturaleza y función del sacrificio (1899) y el Esbozo de una teoría general de la magia (\& Hubert 1901), radica en que a través de ellas el tótem, el sacrificio y la magia son observados menos como instituciones sociales, que como unas lógicas o técnicas definidas más por su forma que por su contenido. A juicio de Delgado aquí se establecería la diferencia clave respecto a la obra de Durkheim Formas elementales de la vida religiosa (1912), pues esta se aproximaría mucho más a una teoría general sobre la religión como institución caracterizada por unos determinados contenidos. Por el contrario, en cuanto técnicas, la clasificación totémica, el sacrificio o la magia constituirían unas operaciones comunicativas orientadas a enlazar dos planos ontológicamente diferenciados. En el caso del sacrificio, por ejemplo, el shock derivado de este ligamiento sería tan fuerte que lo sacrificado debe ser destruido simbólica o realmente. En cuanto técnica el sacrificio permitiría en una misma operación comunicativa poner en juego la cuestión del límite de lo social, pues se trata de una operación realizada en el plano de la paradoja: en la medida que une dos planos ontológicos diferenciados los separa. Ahora bien, es preciso comprender que tal función se hace factible en la medida que, en este caso, el sacrificio no se constituye como una institución de la sociedad. Eric Wolf (1999) en su estudio sobre la ideología ha mostrado hasta qué punto técnicas como el potlatch entre los Kwakiutl o el sacrificio humano entre los aztecas, en la medida que devienen institucionalizadas socialmente, adquieren como principal función la legitimación 
ideológica de las diferencias de poder y estatus. Se trata entonces de un terreno muy sutil que la observación etnográfica debe enfrentar.

Tomemos el caso de la magia como técnica, quizás menos adjunta a una institucionalización. Para Mauss, magia y religión se estructuran en torno a una misma problemática, la de ligar dos planos de la realidad, lo visible y lo invisible, esto es, lo social con aquello que está tras el umbral de lo social. Magia y religión se diferencian entonces a partir de las condiciones en que se practican: mientras la religión es pública e institucionalizada, el rito mágico se realiza en privado y no alcanza a constituirse como institución social. No por ello se trata de un asunto privado, doméstico. A través de la magia, asegura Mauss, se pone en juego la posibilidad de observar aquello que se escapa a la clasificación social. Su eficacia radica en la posibilidad de establecer unas síntesis entre causas y efectos separados, en crear y transformar lo social a través del rito. Tal como señala Lévi-Strauss en la Introducción a Mauss el pensamiento mágico tiene como función aplicar unos esquemas para organizar la experiencia 'objetivando estados subjetivos, formulando lo informulable, integrando a un sistema lo desarticulado', en definitiva, indicando un orden latente que garantiza un orden patente.

Estos episodios comunicativos, la magia, el sacrificio, constituyen entonces mecanismos a partir de los cuales la sociedad se autobserva reintroduciendo un entorno externo sobre el cual no es posible comunicar (invisible, informulable, subjetivo, desarticulado). La presencia y centralidad de estos ritos en sociedades diferenciadas a partir de segmentos permiten establecer a partir de esa negociación con lo que se encuentra más allá de lo social una identidad definida, un orden patente. Se pueden señalar como los entornos privilegiados a partir de los cuales la sociedad se autobserva el mundo como espacio natural, por una parte, y el mundo como espacio animista, por otra. La naturaleza y lo sagrado (animismo) aparecen entonces como aquellos entornos a partir de lo cual se pone en cuestión la reproducción comunicativa de la sociedad, y como aquello que debe ser reintroducido socialmente para permitir la continuación de la autopoiesis. Por otra parte, se puede también señalar que en la medida que por ejemplo el establecimiento del mago y de su eficacia es un hecho que compromete a la colectividad completa, la identidad que se reintroduce a través de tales técnicas no solo compromete a toda la colectividad, sino que se establece en continuidad con un orden cósmico. Durkheim y Mauss escriben sobre las formas totémicas de clasificación: "Se trata de que si, por un lado, el totemismo es la agrupación de los hombres en clan siguiendo el orden de los objetos naturales (especies totémicas asociadas), también representa, a la inversa, una agrupación de los objetos naturales siguiendo el orden de los agrupamientos sociales" (1901: 24). La sociedad se estructura de esta forma en continuidad directa con aquello que está más allá de sus límites, insertándose en un orden cósmico que todo lo incluye. Para ello encuentra en la analogía la herramienta clave.

Si bien Durkheim y Mauss señalan la persistencia histórica que tendrían tales formas de clasificación, actualizadas bajo una forma científica, de ello no se deduce que los mecanismos de autobservación de la sociedad permanezcan inalterables frente a los cambios estructurales en la forma de diferenciación de la sociedad. Si se toma el caso de sociedades diferenciadas no a partir de segmentos, sino a partir de estratos verticalmente ordenados, la pregunta por las formas de autobservación, encontrará unas respuestas diferentes. Aquello que Weber ha referido como proceso de desencantamiento del mundo resulta quizás clave para comprender el bajo rendimiento que formas de autobservación como las descritas alcanzarían para representar la identidad de sociedades diferenciadas a partir de criterios distintos. El desencantamiento del mundo refiere al proceso a través 
del cual la naturaleza deja de ser el referente a partir del cual lo social adquiere sentido; esto es, el proceso a partir del cual la naturaleza deja de constituir el entorno externo privilegiado a partir del cual la sociedad reflexiona sobre sí misma. El problema de la teodicea, simbolizado en el sufrimiento de Job, expresa precisamente la fractura que se produce entre lo que es y lo que debe ser, y que permite la objetivación e instrumentalización del mundo (lo real). En el análisis de Weber, esta experiencia es la que tiene por origen un distanciamiento radical entre Dios y el hombre, distanciamiento que se elabora doblemente como una acentuación de la trascendencia de Dios y como una desvalorización radical del mundo. Así mientras la naturaleza aparece como entorno privilegiado en aquellas sociedades diferenciadas a partir de segmentos, es Dios como figura trascendente y fuera del mundo, el que aparece como entorno externo privilegiado en sociedades diferenciadas verticalmente. Weber señala precisamente que es la esclavitud y sufrimiento del pueblo israelí aquello que activa una solución teocéntrica al problema de que el mundo no es como debe ser. Yahvé es un dios invisible, poderoso, pero salvífico, y es a partir de él que lo social adquiere sentido. Al igual que en el caso de las técnicas rituales, es el profeta aquí quien establece una mediación entre Dios y el hombre, es a través del discurso del profeta cómo se comunica sobre la unidad de lo social.

Ahora bien, este tipo de reintroducción de la diferencia define la identidad de la sociedad no tanto a partir de una estructura analógica entre lo visible y lo invisible, sino a partir de una forma representacional. La sociedad no forma en ese sentido parte de un todo cosmológico al que se integra analógicamente; la sociedad es desvalorizada pues Dios se encuentra fuera de sus límites. La unidad de la diferencia se encuentra fuera de lo social, tiene entonces una prioridad jerárquica y la sociedad solo puede representarla, no integrarla analógicamente.

La modernidad ha sido definida por Luhmann como un proceso de diferenciación funcional. Lo forma moderna de la sociedad emerge entonces en la medida que se estructuran sistemas sociales diferenciados en torno a unos problemas específicos. Así por ejemplo la economía emerge como sistema diferenciado articulado en torno al problema de la escasez, la política en torno al problema de la diferencia de intereses, el derecho respecto a la definición de lo justo, la ciencia respecto a la verdad, etc. Ninguno de estos sistemas tiene como función la elaboración de soluciones definitivas a estos problemas, sino que simplemente reproducen comunicaciones en torno a estas problemáticas. En ese sentido, por ejemplo, la economía como sistema no se encuentra orientada a la resolución del problema de la escasez. Esto, pues, cada sistema tiene como telos su propia reproducción.

Ahora bien, la constitución histórica de sistemas funcionalmente diferenciados no acontece de un momento para otro. La modernidad en ese sentido constituye un proceso de diferenciación funcional que está lejos de acabarse y, a través del cual, cada uno de estos sistemas va adquiriendo mayor autonomía. El paso desde una forma estratificada de diferenciación de la sociedad hacia una por funciones no se ha producido súbitamente. Por el contrario, es posible reconocer estadios intermedios de diferenciación en los cuales ambos elementos, estratos y funciones, definen la forma de la sociedad. Además hay que señalar que la emergencia de una forma de diferenciación, como sería la funcional en la modernidad, no anula o reemplaza las anteriores. Se trata de formas de diferenciación que coexisten, volviendo mucho más complejo el ordenamiento social. Es posible señalar a las clases sociales como principio de diferenciación característico del tránsito hacia una forma funcional de diferenciación. Las clases surgen entonces como una redefinición del 
principio de estratificación articulada en torno a criterios funcionales, específicamente el acceso al dinero y al poder. Su presencia nos indica la temprana diferenciación de los sistemas económico y político.

En Is sociedades diferenciadas por clases sociales, que Marx ha descrito en profundidad, la autobservación social adquiere también una forma específica. Desde la filosofía, por ejemplo, se elabora una particular observación sobre aquello que constituiría la invisibilidad propia de la modernidad. Desde Descartes se declara la imposibilidad de que Dios constituya a priori un entorno externo relevante para la sociedad. Tal como ha señalado Beriain la emergencia del hombre como nuevo centro expresaría la "fragmentación del arquetipo central, que tiene su expresión en el nivel del mito y, que en un principio se acoge a una posición de posibilidad única, de 'todo en uno', y, representa la perfección, la totalidad" (Beriain 2000: 107). La reflexión de Heidegger sobre el carácter de la modernidad busca señalar como principal característica de la modernidad la reivindicación del hombre sobre los principales atributos de dios ahora con minúscula: omnisciencia y omnipotencia. Tal como señala Renaut (1989: 39) en Heidegger 'toda manifestación de la modernidad es deducida de la llegada de la subjetividad". Tal interpretación de la modernidad a partir de la idea de sujeto ha encontrado en la sociología una especial recepción. La modernidad se ha observado entonces regida a partir de los dos principios constitutivos del sujeto: la prioridad de la conciencia sobre la existencia (despliegue racionalidad ilustrada) y la primacía de la voluntad sobre la experiencia (despliegue racionalidad instrumental). La emergencia de esta figura del sujeto, que llega a su máxima expresión en la reflexión kantiana sobre la autonomía, resulta característica del tránsito hacia una nueva forma de diferenciación social distinta de la estratificada.

Ahora bien, a partir de estos principios de la reflexión filosófica sobre la modernidad es posible pensar en la forma que asume la autobservación de una sociedad diferenciada por clases como estructurada a la idea de sujeto. A ello, sin embargo, Marshall Sahlins añade un nuevo elemento toda vez que ha señalado que "el materialismo histórico es, en verdad, la toma de conciencia de sí misma de la sociedad burguesa, y sin embargo, se diría, una toma de conciencia dentro de los términos de esa sociedad' (1976: 166). Debemos pensar entonces que la definición de un entorno externo en la sociedad burguesa -diferenciada por clases - no se encuentra orientada exclusivamente por la idea de sujeto, sino también por la introducción de ese sujeto en la historia. La historia de la sociedad pensada bajo la idea de progreso y la emergencia de un sujeto histórico, que 'realiza' ese progreso, parecen ser las claves para pensar en la forma cómo este tipo de sociedad se observa a sí misma. A partir de este sujeto histórico, la sociedad puede entonces observarse a sí misma como un proceso dialéctico, proceso derivado de las contradicciones resultantes de la coexistencia de distintos tipos de sujetos -campesinos vs urbícolas, burgueses vs proletarios, etc. En ese sentido, no se trata de la capacidad de una clase para elaborar una representación totalizante de la sociedad, sino un proceso de contradicciones y síntesis.

En este proceso, la identidad de lo social no se elabora ni por analogías cosmogónicas ni por una trascendentalización de Dios. Lo social es definido históricamente, como un momento dentro de un proceso histórico superior. Y la forma como se experiencia esta identidad históricamente elaborada debe radicar en la experiencia del cambio y de la revolución. Así, desde las primeras revoluciones campesinas durante la edad media tardía, hasta los últimos movimientos revolucionarios representados por Mayo del 68, e incluyendo también las revoluciones burguesas de los siglos XVII y XVIII y las 
revoluciones proletarias del siglo XIX, deben todas considerarse formas sociales en que se reintroduce y experiencia el entorno externo característico de la sociedad diferenciada por clases: el sujeto histórico.

\section{CUADRO 1: AUTOBSERVACIÓN DE LA SOCIEDAD.}

\begin{tabular}{|c|c|c|c|c|}
\hline $\begin{array}{l}\text { FORMADE } \\
\text { DIFERENCIACIÓN }\end{array}$ & $\begin{array}{c}\text { POR } \\
\text { SEGMENTOS }\end{array}$ & $\begin{array}{c}\text { POR } \\
\text { ESTRATOS }\end{array}$ & POR CLASES & $\begin{array}{c}\text { POR } \\
\text { FUNCIONES }\end{array}$ \\
\hline $\begin{array}{l}\text { Entorno ex terno } \\
\text { privilegiados para } \\
\text { autobservación.. }\end{array}$ & $\begin{array}{c}\text { La Naturaleza } \\
- \\
\text { Lo Sagrado. }\end{array}$ & Dios & $\begin{array}{l}\text { Sujeto } \\
\text { Histórico }\end{array}$ & Individuo \\
\hline $\begin{array}{l}\text { Lógica de } \\
\text { Autobservación } \\
\text { Societal. }\end{array}$ & Analogía & Representación & Dialéctica & Comparación \\
\hline $\begin{array}{l}\text { Forma de } \\
\text { Reintroducción del } \\
\text { entorno }\end{array}$ & Totalizante & Categorizante & Contradictoria & Acéntrica \\
\hline $\begin{array}{l}\text { Identidad derivada } \\
\text { de autobservación. }\end{array}$ & $\begin{array}{c}\text { Identidad } \\
\text { Cosmogónica }\end{array}$ & $\begin{array}{l}\text { Identidad } \\
\text { Jerárquica }\end{array}$ & $\begin{array}{l}\text { Identidad } \\
\text { Histórica }\end{array}$ & $\begin{array}{l}\text { Identidad } \\
\text { Cultural }\end{array}$ \\
\hline $\begin{array}{l}\text { Ejemplos de } \\
\text { Mecanismos de } \\
\text { autobservación }\end{array}$ & Rito mágico & $\begin{array}{l}\text { Experiencia } \\
\text { Profética }\end{array}$ & Revoluciones & $\begin{array}{l}\text { Espacios } \\
\text { Públicos } \\
\text { Urbanos }\end{array}$ \\
\hline
\end{tabular}

El proceso diferenciación funcional antes señalado como característico de la modernidad permite observar la emergencia de una nueva invisibilidad, esto es, la emergencia de un nuevo entorno extorno privilegiado a partir del cual se reflexiona sobre el límite de la comunicación. Volviendo a la filosofía podemos encontrar en Alain Renaut una profunda crítica a la interpretación heideggeriana de la modernidad como constituida en torno a la idea de sujeto. La tesis central que sostiene Renaut es que tal interpretación atribuye una excesiva unidimensionalidad a la historia de la subjetividad, reduciendo la especificidad de sus distintos momentos: cogito racionalita, cogito empirista, cogito criticista. De lo que se trata entonces, señala Renaut, es de reconstruir la historia plural y discontinua de las distintas subjetividades. El análisis de esa historia plural del 'sujeto' conduce a "una mutación radical, la que, en la historia del sujeto conduce del sujeto al individuo, ... sería tentador pensar que a partir de Leibniz se ha tratado menos de una historia de la subjetividad que de una historia de la individualidad" (1989: 55). Lo que Renaut propone entonces es pensar la filosofía de la modernidad como articulada en torno a la idea de individuo antes que a la de sujeto. Más allá de la 'verdad' de este análisis, lo relevante es que se trata de una reflexión característica de la segunda mitad del siglo XX. Y la observación de la primacía del individuo no es algo propio de la filosofía. No deja de ser curioso, por ejemplo, que la teoría a partir de la cual se elabora este análisis de la cultura, la teoría de los sistemas autopoiéticos, sostenga un concepto de lo social como algo irreducible a lo individual, lo que supone una concepción del individuo como algo, también, irreducible a lo social. Individuo y sociedad aparecen como complejidades 
distintas, irreductibles la una a la otra. Se puede recurrir al cine, a la literatura, a los documentos etnográficos, no importa, en este caso es en la filosofía donde encontramos una sugerencia clave para pensar en la constitución del entorno externo de la sociedad moderna: el individuo.

Si se acepta la sugerencia de que el individuo constituye aquello que se observa como esencialmente irreducible, como aquello a partir de lo cual se pone en cuestión la reproducción autopoiética de la sociedad, la atención debe entonces dirigirse hacia los espacios sociales donde aparece el individuo como alteridad radical, como contingencia pura, como indeterminación total. En este punto no es posible no volver a los análisis de Manuel Delgado sobre el espacio público urbano. La calle constituye a juicio de Delgado el espacio donde se experimenta la modernidad en un sentido radical. En el análisis de Delgado se observa lo urbano como un espacio en constante estructuración y desestructuración, en el cual no alcanza a constituirse una institucionalización de la experiencia social, pues sus usuarios son siempre transeúntes que están allí sólo de paso. Por lo mismo lo urbano constituiría "un territorio desterritorializado, que se pasa el tiempo reterritorializándose y volviéndose a desterritorializar ... también porque en su seno todo lo que concurre y ocurre es heterogéneo" (1999: 46). Delgado piensa entonces en el espacio público como un espacio liminal donde lo social se pone entre paréntesis y donde el transeúnte no se encuentra presente como miembro de la comunidad. Por el contrario, aparece en un contexto de alteridad generalizada, nada se sabe de él porque nada se muestra, y por lo tanto todo es posible, su presencia es pura ausencia y contingencia. El transeúnte aparece entonces como "nadas ambulantes, perfiles nihilizados, seres hipertransitivos, sin estado, es decir que no pueden ser contemplados estáticamente, sino sólo en excitación, trajinando de un lado para otro" (201). De esta forma, asegura Delgado, la calle aparece como la experiencia más radical del límite no social de la sociedad. Lo que aparece entonces es el individuo en su contingencia y alteridad más absolutas. La calle constituye así un espacio privilegiado, en ningún caso el único, desde donde se experimenta el límite de la comunicación socialmente determinada y ordenada.

Habría que pensar en el tipo de reflexión sobre la identidad de la sociedad a que da lugar la experiencia del individuo como límite a-social de la sociedad. En la medida que lo que se observa es un magma de elementos dispersos (individuos) y reunidos sin ninguna estructura ordenadora, el individuo como entorno externo de la sociedad es reintroducido comparativamente. El individuo no se observa aquí ni a partir de una analogía respecto a la cual la sociedad se pueda observar en continuidad, ni como aquello que contiene la unidad de lo diferenciado. Se trata de una suma de individuos dispares, irreductibles, como una suma infinita de entornos externos, que solo se pueden comparar unos a otros y que la sociedad debe seleccionar para observarse a sí misma. En su diversidad los individuos son observados como elementos culturales, y el tipo de identidad que la sociedad adquiere por la reintroducción del individuo, de un tipo de individuo, como su entorno externo, es una identidad cultural, acéntrica.

\section{ii. Heterobservación e Institucionalización}

Se ha señalado al comienzo que la heterobservación de la sociedad constituye un proceso continuo y ligado a cada situación comunicativa, pues refiere a la observación implícita de la sociedad que cada comunicación orientada en torno a un sistema parcial requiere para seguir refiriendo al sistema. Así, en la medida que se ha considerado la heterobservación como un aspecto constituyente de la cultura de la sociedad, todo lo que 
se comunica en sociedad está mediado culturalmente. Sin embargo, ello no implica que se pueda considerar, junto con antropólogos como Geertz, que los distintos sistemas funcionales de la sociedad, la religión, la política, el sentido común, constituyan sistemas culturales. Lo que aquí se argumenta es que la operación sistémica se encuentra ligada, pero no es constituida ni cons titutiva de la cultura. La cultura de la sociedad se constituye en el lado no indicado por la observación y comunicación sistémica.

Seguir la sugerencia de Geertz, y considerar los sistemas sociales como sistemas culturales, nos llevaría a disolver el concepto de cultura que se ha venido elaborando. Ya se ha señalado el carácter a-sistémico de la autobservación de la sociedad, su constitución en el límite de lo social, en una interacción fugaz que apenas alcanza a constituirse como sistema interaccional porque lo que está en juego es la mismo comunicación, y que recuerda la metáfora que Appadurai elabora para la cultura como formas fractales fugaces, superpuestas, politéticas. Estos espacios antes de estar ordenados simbólicamente, ponen en juego la capacidad simbólica, y constituyen, tal como señala Delgado, el fundamento de lo social. Si pensamos en la heterobservación simplemente como el otro lado de la autobservación, como lo ordenado sistémicamente, la definición de cultura hasta aquí elaborada pecará de difusidad. Si la cultura es la autobservación y la heterobservación de la sociedad, y la primera refiere a lo a-sistémico mientras que lo segundo a lo sistémico, la cultura lo constituiría todo, y entonces cuál podría ser la utilidad científica de tal concepto.

Pero hay que señalar una segunda cuestión, más importante. Cuando Geertz señala el carácter de sistema cultural que tendría la religión, lo hace en virtud de que ella se constituiría como un sistema de símbolos. Lo cultural queda entonces definido por lo simbólico y por su ordenamiento sistémico. Es de ello que se deducen las restantes características de, por ejemplo, la religión como sistema cultural: su observación (concepción) total de la sociedad desde sí misma, su efectividad en la producción de realismo, su influencia en los estados de animo y motivaciones de los seres humanos. Comprender exactamente lo que quiere decir un sistema de símbolos es clave entonces para preguntarnos si lo que hemos señalado como heterobservación de la sociedad puede comprenderse como un elemento simbólico.

En el análisis de Geertz un símbolo es definido como todo aquello -sea un objeto, un acto, una cualidad, una relación- que opere como vehículo para una concepción; concepción que constituiría el significado del símbolo. Se trata de "formulaciones tangibles de ideas, abstracciones de la experiencia fijadas en formas perceptibles, representaciones concretas de ideas, de actitudes, de juicios, de anhelos o de creencias" (Geertz 1973: 90). En ese sentido constituyen 'fuentes extrínsecas de información' que operan como 'modelos de' la realidad, esto es, como un complejo de concepciones que permite elaborar y ajustar la realidad no simbólica a sí mismas. De esta forma lo simbólico es aquello que da sentido, pues en la medida que se ajusta a la realidad social, la elabora conceptualmente. En ese sentido Geertz señala que "los esquemas culturales -religiosos, filosóficos, estéticos, científicos, ideológicos- son 'programas'; suministran un patrón, un modelo para organizar procesos sociales y psicológicos" (1973: 189)

Junto a esta concepción de lo simbólico, la posición señalada por Luhmann resulta sumamente cercana. Luhmann refiere a los procesos de generalización simbólica como aquellos que permiten la atribución de una unidad a una pluralidad. Tal como señala Geertz, a juicio de Luhmann las generalizaciones simbólicas son elaboradas en el trato concreto con objetos y acontecimientos y operan como "denominaciones globales, como 
representaciones de tipos, como conceptos heterogéneos sobreabarcadores que pueden ser incorporados al mundo pleno de sentido sólo con ayuda del lenguaje" (Luhmann 1984: 105). Una forma específica que reciben estas generalizaciones simbólicas es como medios de comunicación, se podría decir como lenguajes. Los medios simbólicamente generalizados de comunicación, a diferencia del lenguaje sin embargo, permiten representar la relación entre las motivaciones y la comunicación seleccionada como una unidad. Así operaría la verdad, el dinero, el poder, el derecho, lo estético, etc. Estos medios simbólicamente generalizados de comunicación son constituyentes de los sistemas sociales funcionalmente diferenciados. La ciencia se estructura en torno al medio verdad, la política en relación al poder, la economía al dinero, el arte a lo estético, etc.

Ahora bien, cuando se hace referencia a la heterobservación como un proceso social continuo, se refiere a lo que se encuentra velado en las comunicaciones orientadas por estos medios simbólicamente generalizados. La religión, tal como observa Geertz, constituye un sistema simbólico autorreferente que reduce todo lo social a sí mismo, pero para hacerlo debe operar una distinción entre lo religioso y lo no religioso, debe señalar una diferencia con su entorno, pues sino en cuanto sistema se diluiría en la complejidad de su ambiente. La autorreferencia sistémica permite entonces enlazar comunicaciones en la medida que estas apuntan hacia el lado positivo del código, lo religioso. El otro lado es dado por supuesto, no es doservable directamente, pero es lo que posibilita que la comunicación sea religiosa y no otra cosa. Esa alteridad es la sociedad, heterobservada sistémicamente. Si entendemos entonces lo simbólico como aquello que tiene como significado una concepción (Geertz), como aquello que como unidad representa una pluralidad (Luhmann), habrá que señalar el carácter no simbólico de la heterobservación de la sociedad, pues la sociedad aparece aquí como pura diferencia. Ni concepción, ni unidad; habrá que decir, parafraseando a Derrida, que la sociedad aparece aquí como pura alteridad. La observación de esta alteridad pura, la heterobservación, constituye un proceso opaco, velado, constitutivo de la cultura de la sociedad como entorno interno, y en cuanto entorno, no directamente observable.

En Cultura y Razón Práctica (1976), Marshall Sahlins, a diferencia de Geertz, establece una clara diferenciación entre el orden cultural de la sociedad y su estructura funcional, que puede ser útil para definir aún más lo hasta aquí propuesto, aun cuando sea nuevamente por oposición. El problema que se observa es que la elaboración de esta distinción se basa en la atribución de un carácter meramente pragmático a los sistemas funcionales de la sociedad, reservando así el espacio del significado, de lo simbólico, para el orden cultural. A partir de tal distinción Sahlins señala que el orden cultural como sistema significativo "es lo que define toda funcionalidad; es decir, la define de acuerdo con la estructura particular y las finalidades del orden cultural. De ello resulta que ninguna explicación funcional es jamás suficiente por sí misma; en efecto, el valor funcional siempre es relativo respecto del esquema cultural dado" (Sahlins: 204).

Es necesario comprender que la propuesta de Sahlins se encuentra elaborada como una crítica directa a aquellos que siguiendo la tradición de Morgan se identificarían con una visión pragmática de lo social. Sin embargo, al reemplazar la determinación pragmática de lo social por una determinación exclusivamente cultural, Sahlins no hace más que invertir el supuesto básico del pensamiento iluminista. Tal como ha señalado Morandé (1983) en referencia a las sociologías de la modernización, al liberalismo y al marxismo, tal principio se basa en indicar una identidad entre el espacio de los valores y la funcionalidad de las estructuras de la sociedad. Tal principio descansaría en "un concepto límite de sociedad 
maximizada donde la racionalidad de los medios y la racionalidad de los fines se identifican" (Morandé 1983: 74). La posición hasta aquí desarrollada se distancia entonces de la distinción entre cultura y estructura funcional planteada por Sahlins en un doble sentido: por una parte, no niega el carácter simbólicamente constituido de los sistemas funcionales de la sociedad, y por otra, pretende señalar el orden cultural como algo completamente distinto, ni constituido ni constituyente de tal orden simbólico-funcional.

Hay que señalar entonces que la heterobservación de la sociedad no puede constituir un sistema funcionalmente diferenciado, pues resulta mas bien como producto colateral de la actividad sistémica. Por lo mismo, y de la misma manera que la autobservación de la sociedad, posee un carácter politético, o policontextual para retomar el concepto de Luhmann. La multiplicidad de heterobservaciones resultantes como externalidades del operar sistémico refieren ante todo a la forma de la diferenciación de la sociedad. Si se sigue la sugerencia planteada en el apartado anterior respecto a la posibilidad de indicar una suerte de fenómeno social total como espacio social privilegiado donde se condensan los procesos de heterobservación de la sociedad, la pregunta respecto a cómo se vuelven estas heterobservaciones 'visibles' socialmente puede encontrar su respuesta en el ámbito de la institución.

Marshall Sahlins ha explorado precisamente la centralidad de lo que el denomina diseño institucional en la forma como la sociedad se comprende a sí misma. Lo interesante de la propuesta de Sahlins es que establece una clara distinción entre el orden cultural de un sociedad y la descripción que ésta recibe de sí misma a través de unas ciertas instancias institucionales. Sin embargo, dadas las diferencias anotadas anteriormente respecto a la postura de Sahlins, tampoco es posible pensar aquí en una suerte de diseño institucional de la sociedad. Tal planteamiento se basa en que el orden simbólico de la sociedad -su cultura- se originaría a partir de los procesos de producción simbólica arraigados en unos espacios institucionales privilegiados: el parentesco en las sociedades segmentadas, el estado y la religión en las sociedades estratificadas, la economía en la sociedad moderna. La posibilidad de un diseño institucional de la sociedad supone aquello que Bourdieu ha denominado como homologías estructurales de los distintos campos de la sociedad o lo que el mismo Sahlins propone como sinapsis simbólicas. Esto es, "conjunciones de oposiciones provenientes de distintos planos culturales que adoptan la forma de diferenciaciones homólogas" (1976: 213-214). Tales homologías solo podrían ser constituidas entonces a partir de una unidad cultural final, aquello que Sahlins denomina como un 'código general de significación' que opera como 'identidad cualitativa' de la sociedad.

Sin embargo, la función sistémica del entorno interno de la sociedad no se puede analogar a lo planteado por Sahlins. Si bien es por diferenciación respecto a este entorno como cada sistema parcial adquiere su identidad, de ello no se deduce que este entorno conserve algo así como 'la identidad cualitativa' de la sociedad. La sociedad se posiciona aquí como un sistema en el entorno de los sistemas parciales, es decir, como horizonte para su diferenciación estructural. El problema de la identidad de la sociedad refiere a un tipo de operación distinta, a saber, aquella a partir de la cual la sociedad como sistema total de comunicaciones reflexiona sobre la propia comunicación. Tal 'reflexión' requiere necesariamente la reintroducción de un entorno no comunicacional, no social, en la propia sociedad; entorno que ya hemos ejemplificado como la Naturaleza, Dios o el Individuo. Resulta necesario entonces pensar en lo institucional como aquel espacio privilegiado a partir del cual se representa, no la identidad de lo social, sino el conjunto disperso y 
politético de heterobservaciones (observaciones realizadas por sistemas parciales) de la sociedad, y a través de ellas, la estructura de diferenciación de la sociedad.

Sin pretender aquí reproducir, criticar, ni mucho menos adherir al pensamiento de Cornelius Castoriadis, sino simplemente pensar en la institución de las heterobservaciones de la sociedad, se retoma a continuación algunas ideas de las que propone para comprender lo que denomina 'la institución imaginaria de la sociedad'. Ya hemos establecido que la heterobservación de la sociedad no es un proceso simbólico, sino una suma de indicaciones veladas sobre el entorno de los sistemas parciales de la sociedad. Es posible pensar en esta suma de indicaciones como en aquello que Castoriadis califica como un magma: "aquello de lo cual se puede extraer (o, en el cual se puede construir) organizaciones conjuntistas en cantidad indefinida, pero que jamás puede ser reconstruido (idealmente) por composición conjuntista (finita ni infinita) de esas organizaciones" (Castoriadis 1975: 288). En términos sistémicos, decimos que se trataría de una suma de elementos en acoplamiento amplio (médium) a partir del cual pueden elaborarse múltiples acoplamientos estrictos (formas), pero nunca una reconstrucción simbólica única de todas sus posibilidades. Ahora bien, la 'institución imaginaria de la sociedad' refiere precisamente refiere al proceso a través del cual la sociedad elabora a partir de tal magma unas determinadas significaciones imaginarias, a partir de las cuales lo social se vuelve posible y adquiere una mínima coherencia. En los términos aquí desarrollados, tal proceso de institucionalización de las heterobservaciones, de atribución de unos determinados significados al entorno interno de la sociedad, permitiría la diferenciación de los sistemas parciales de la sociedad respecto a un entorno del mismo tipo, respecto a un entorno institucionalizado. Tampoco para Castoriadis se trataría de una institución fija en el tiempo o trascendente respecto al presente; señala: "la sociedad instituye en cada momento un mundo como su mundo o su mundo como el mundo, ... La sociedad da existencia a un mundo de significaciones y ella misma es tan sólo en referencia a ese mundo" (1975: 312). Ahora bien, aunque Castoriadis no atribuya una prioridad histórica a tal tipo de institución de lo social, sí le atribuye una prioridad lógica. Se trata de un tipo de institución bien distinta a la de Sahlins, es cierto, pero le es atribuible la misma crítica: Si bien es por diferenciación respecto a este entorno (institucionalizado) como cada sistema parcial adquiere su identidad, de ello no se deduce que este entorno sea anterior, pues existe sólo conjuntamente con la operación de diferenciación sistémica; como dice Luhmann, el entorno es co-dado con el sistema. Sin embargo, es posible pensar ahora en la institución, no como derivada de un sistema funcional específico (Sahlins), sino como el proceso de construcción social del entorno, de reducción de complejidad del magma.

Ahora bien, se trata entonces de pensar en lo institucional de una forma completamente distinta a cómo habitualmente lo hacemos. De una forma tan distinta que cuesta insistir en denominarla institución. Bennington y Derrida (1991) señalan dos características fundamentales de lo que Derrida entiende por institución: a. Aquello que posee una autonomía suficiente como para reconocer la alteridad elaborada a partir de sí misma, es decir, "lo bastante autónoma como para reconocer la imposibilidad de la autonomía", y b. Aquello que es "lo bastante sensible a la existencia de dicha alteridad como para deshacerse y reconstituirse a un ritmo muy rápido" (Bennington \& Derrida 1991: 270). Dos de las metáforas allí señaladas pueden ayudar a la comprensión de los límites entre los que se mueve tal tipo de institución: ni torre de marfil, ni de Babel; ni indiferencia a las diferencias sistémicas respecto al entorno interno de la sociedad, ni apertura absoluta a estas. La posibilidad de tal institución, señala Bennington,, viene dada por su orientación al acontecimiento, se trata entonces de una institución que existe en cuanto es capaz de 
articularse como suma de acontecimientos: "una meta o idea esencial sería la siguiente: que suceda algo, que algo pase, que haya un acontecimiento" (1991: 270). Solo así, entendemos, es posible pensar en una institución constituida por referencia a las múltiples heterobservaciones de la sociedad, pues éstas acontecen sólo a través de los episodios comunicativos.

Si se trata, en definitiva, de aquello imaginado en cada acontecimiento, aunque no necesariamente comunicado, es posible pensar en la institucionalización del entorno interno de la sociedad como una serie de propiedades estables a la operación de los distintos sistemas parciales. En Observaciones a la Modernidad Luhmann hace una oscura referencia a estas propiedades: "Habría que esperar que en el ejercicio de esas operaciones (observaciones) resultaran propiedades, es decir, posiciones que se mantuvieran estables y no cambiaran en el sucesivo operar del observador" (citado por Pintos: 130). Lo que aquí se ha señalado respecto a la institucionalización del entorno interno de la sociedad coincidiría con esas propiedades no observables a las que refiere Luhmann.

Quizás la mejor forma de indicar estas propiedades sea buscar algunos modelos históricos de institucionalización de las heterobservaciones. Para ello la antropología proporciona los documentos etnográficos claves para observar la 'realidad' de lo que indican estas formulaciones teóricas. Tal tarea, sin embargo, formaría parte de un trabajo largo y complejo que queda por hacer. Por ahora baste señalar algunas sugerencias respecto a los modos de concreción histórica que tal institucionalización de la heterobservación de la sociedad pudiera tener. Pensando por ejemplo en la amplia documentación etnográfica respecto a sociedades que encuentran como principio clave de diferenciación social la segmentación, es posible pensar que el entorno a partir del cual cada segmento se diferencia y adquiere una identidad homóloga hará referencia a la sociedad como un todo homogéneo. Los principios de homología y analogía estructural que presentarían entonces los distintos segmentos implicarían que la diferenciación de cada uno de ellos se realiza por referencia a una unidad que los incluye: por ejemplo, 'lo colectivo'. Si es a través de lo colectivo como 'institución imaginaria de la sociedad' cómo se representa la estructura de diferenciación social, es posible pensar que el modo de acceso privilegiado a esa unidad anterior a las diferencias estructurales de la sociedad se realiza a través de lo mítico. La observación mítica permite reconstruir la unidad de lo diferenciado en un espacio y tiempo exterior a las diferencias segmentarias existentes. La actualización social de tales observaciones míticas sobre la unidad homogénea de lo social pueden encontrar un mecanismo privilegiado en la construcción genealógica de lo social. A través del mito en general y de la reconstrucción genealógica en particular, cada segmento (sistema) se diferencia respecto a lo colectivo, sin perder de vista la unidad que constituye la forma de diferenciación de la sociedad.

Un tipo de entorno interno completamente distinto constituiría a las sociedades que en términos amplios se caracterizan por diferenciarse principalmente a través de una estructura estratificada. En este tipo de sociedades cada sistema parcial se diferencia respecto a unos criterios externos (propiedades) que lo identifican en una posición determinada dentro de una jerarquía. De este modo, de la estructura de diferenciación que se representa a través de este entorno interno de la sociedad se derivan unas diferencias cualitativas entre un sistema y otro. Es posible pensar en 'lo superior' como una forma de institucionalización de tal entorno, esto es, pensar en 'lo superior' como aquello heterobservado en los procesos de diferenciación de los distintos sistemas parciales. Como hemos señalado, tal entorno interno de la sociedad no es observado 
directamente, sino heterobservado. Sin embargo, la improbabilidad asociada a la forma de diferenciación jerárquica entre los sistemas parciales de una sociedad, requiere la 'presencia' de tal criterio de diferenciación -lo superior- en todos los espacios y en todas las situaciones de la vida, a fin de que la sociedad como un todo se subordine a su forma específica. Así, es posible pensar que la forma como socialmente se observa la unidad de la sociedad es a través de la observación de un 'ethos', esto es, de una forma siempre presente como criterio para las prácticas sociales. Por lo mismo, no se puede presuponer que en los episodios comunicativos a partir de los cuales se construye tal entorno interno de la sociedad, estas diferencias de rango sean directamente percibidas desde los distintos sistemas parciales de la sociedad. Eso, además, implicaría suponer que desde los distintos estratos se levantan criterios de comparación comunes a fin de constatar la desigualdad. Por el contrario, hay que pensar más bien que la 'institución imaginaria de la sociedad' a través de un ethos, encuentre como mecanismos sumamente útiles la moralización de las diferencias (9).

Cabe pensar en las sociedades diferenciadas por clases sociales como articuladas en torno a la idea de nación. En la medida que se trata de una forma de diferenciación social en la que se pone en juego la contradicción de intereses de clase, pero que al mismo tiempo encuentra en la política y la economía como sistemas funcionalmente diferenciados mecanismos totales de inclusión, puede pensarse en la emergencia de lo nacional como criterio en torno al cual se diferencia la sociedad. Como criterio de diferenciación de clases, y al mismo tiempo, como marco de referencia de sistemas funcionalmente diferenciados la nación es observada, por antonomasia, como una unidad política. Si bien, tal como ha señalado Hobsbawn en 'La invención de la tradición', se le atribuye a lo nacional una unidad mítica y ética, primeramente se trata de un problema político: pensemos en los requisitos señalados por Weber, monopolio de los medios de administración y dominación, desarrollo de una burocracia racionalmente orientada, monopolio del ejercicio de la ley y uso de la fuerza. Lo nacional como unidad emerge entonces como una unidad política, y cada sistema parcial (clases) se observa a sí mismo como políticamente constituido. Al mismo tiempo, tal estructura de diferenciación social se encuentra estructurada económicamente, esto es, a partir del acceso diferencial al dinero. De esta manera, la sociedad encuentra en la nación un entorno interno para su diferenciación, diferenciación que es observada político-económicamente. 
CUADRO 2: HETEROBSERVACION DE LA SOCIEDAD.

\begin{tabular}{|l|c|c|c|c|}
\hline $\begin{array}{l}\text { FORMADE } \\
\text { DIFERENCIACIÓN }\end{array}$ & $\begin{array}{c}\text { POR } \\
\text { SEGMENTOS }\end{array}$ & $\begin{array}{c}\text { POR } \\
\text { ESTRATOS }\end{array}$ & POR CLASES & $\begin{array}{c}\text { POR } \\
\text { FUNCIONES }\end{array}$ \\
\hline $\begin{array}{l}\text { Entorno interno } \\
\text { privilegiado para la } \\
\text { heterobservación } \\
\text { de la sociedad }\end{array}$ & Lo Colectivo & Lo Superior & La Nación & $\begin{array}{c}\text { Lo Público- } \\
\text { Global }\end{array}$ \\
\hline $\begin{array}{l}\text { Forma de la } \\
\text { heterobservación }\end{array}$ & Mítica & Ética & Política & Politética \\
\hline $\begin{array}{l}\text { Representación de } \\
\text { estructura de } \\
\text { diferenciación }\end{array}$ & Parentesco & Religión & Economía & Información \\
\hline $\begin{array}{l}\text { Ejemplos de } \\
\text { mecanismos de } \\
\text { heterobservación } \\
\text { de la sociedad.. }\end{array}$ & La Genealogía & La Moral & La Ideología & $\begin{array}{l}\text { Los Medios de } \\
\text { Masas. }\end{array}$ \\
\hline
\end{tabular}

Podemos, por fin, volver ahora a lo planteado por Appadurai respecto a lo que constituiría la forma que asumen los procesos culturales en la sociedad contemporánea. En este contexto, sí tiene sentido plantear que la modernidad constituye un proceso continuo de diferenciación y globalización que no puede remontarse a las segunda mitad del siglo XX, sino que, tal como señala Wallerstein por ejemplo, debe remitirse a varios siglos atrás en la historia. Más allá de estas precisiones hay que preguntarse entonces por el tipo de entorno a partir del cual los distintos sistemas parciales de la sociedad adquieren su identidad. Appadurai propone denominar tal entorno como 'lo global', entendiéndolo como una multiplicidad de formas que circulan a través del globo, principalmente por las vías de los medios de comunicación. Lo interesante de la propuesta de Appadurai es que señala que 'lo global' no puede reducirse a lo transmitido por los mass media. Lo global constituiría una referencia constante en la comunicación, pero no reductible a ningún sistema funcionalmente diferenciado. En prácticamente una de las únicas referencias que Luhmann hace a este asunto, señala que lo que constituiría el entorno interno de la sociedad moderna podría calificarse como 'lo público', entendiendo por ello la 'reflexión sobre todo límite de sistema (interno a la sociedad)" (1995). Ahora bien, a través de esta 'institución imaginaria de la sociedad' como lo público-global, la observación que se dirige sobre la forma de diferenciación de la sociedad tendría, tal como señala Appadurai, un carácter politético o policontextual. La referencia a lo público en el operar sistémico (la heterobservación) daría lugar a una observación de la sociedad en la cual ni una unidad mítica, ni ética podrían estabilizarse como criterios de diferenciación. Esa sería la especificidad de la modernidad y que permitiría que mecanismos como los medios masivos de comunicación asumieran, aunque solo en parte, la representación de lo publico como institución de la sociedad. Lo señalado por Derrida respecto a la institución, aquello de que para representar la alteridad que la hace posible debía necesariamente deconstruirse y reconstruirse a cada momento, hace mucho sentido cuando se piensa en la forma como operan los medios de masa. 


\section{Bibliografía Citada.}

Appadurai, Arjun. (1996) Modernity at Large. Cultural dimentions of globalization. University of Minnesota Press. 1998.

Arnold, Marcelo. (1997) Temas metodológicos en la investigación de segundo orden, en revista Anthropos 173/174 'Niklas Luhmann: Hacia una teoría científica de la sociedad'. ps. $145-151$.

\& Fernando Robles (2000). Comunicación y Sistemas de Interacción. Revista del Magíster en Antropología y Desarrollo. Universidad de Chile. 2000.

Beriain, Josetxo. (2000) La lucha de los dioses en la modernidad. Editorial Anthropos. 2000.

Bennington, Geoffrey \& Jacques Derrida. (1991) Jacques Derrida. Editorial Cátedra. 1994.

Castoriadis, Cornelius. (1975) La institución imaginaria de la sociedad. Vol. 2. El imaginario social y la institución. Ediciones Tusquets. 1989.

Cousiño, Carlos. (1990) Razón y ofrenda. Cuadernos del Instituto de Sociología. Universidad Católica de Chile. 1990.

Delgado, Manuel. (1999) El animal Público Editorial Anagrama. Barcelona, 1999.

Durkheim, Emile \& Marcel Mauss. (1901) De ciertas formas primitivas de clasificación en Marcel Mauss. Institución y Culto. Obras II. Editorial Barral. 1971.

Geertz, Clifford (1973) La interpretación de las culturas. Editorial Gedisa. 2001.

Kuper, Adam. (1999) Cultura. La versión de los antropólogos. Editorial Paidós, Barcelona, 2000.

Hobsbawn, Eric. (1983) Introduction. The invention of tradition Cambridge University Press. 1983.

Luhmann, Niklas. (1984) Sistemas Sociales. Editorial Anthropos-Universidad Iberoamericana. España-México, 1998.

(1993) Teoría de la Sociedad. Universidad de Guadalajara - Universidad Iberoamericana. México, 1993.

(1995) La realidad de los medios de masa. Manuscrito inédito traducido por el profesor Javier Torres Nafarrate Actualmente ya se encuentra editado por Editorial Anthropos según la traducción de este mismo profesor. 2000.

(1999) La cultura como concepto histórico. En revista Teoría de los sistemas sociales, II. Chile/México, U. Los Lagos/U. Iberoamericana, 1999. p. 189-213. 
Morandé, Pedro. (1983) Cultura y modernización en América Latina. Ediciones Encuentro. Madrid. 1987.

Pintos, Juan Luis. (1997) La nueva Plausibilidad (La observación de segundo orden en Niklas Luhmann) en Revista Anthropos 173/174 'Niklas Luhmann: Hacia una teoría científica de la sociedad'.

Ramos-Torres, Ramón. (1997) Dios, Epiménides y Tristam Shandy: destinos de las paradojas en la sociología de N. Luhmann en Revista Anthropos 173/174 'Niklas Luhmann: Hacia una teoría científica de la sociedad'.

Renaut, Alain. (1989) La era del individuo. Ediciones Destino. 1993.

Sahlins, Marshall. (1976) Cultura y razón práctica. Editorial Gedisa. 1997.

Wolf, Eric. (1999) Envisioning Power. Ideologies of dominance and crisis. University of California Press. 1999.

\section{Notas}

1) Sobre la realidad de los sistemas sociales y las limitaciones del observador para designar un sistema, véase Luhmann, Niklas. Sistemas Sociales (SS). Editorial Anthropos-Universidad Iberoamericana. España-México, 1998. Pág. 13.

2) Ver bibliografía citada. Esta propuesta adolece, sin embargo, de la revisión de algunos textos que podrían ser claves, a saber, Luhmann, Niklas. Gesselschaftsstruktur und Semantik. Vol I, II, III, IV. Francfort, Suhrkamp, 1980, 1981, 1989, 1995. Luhmann, Niklas. Die Gesselschaft der Gesselschaft. Francfort, Suhrkamp, 1997.

3) Demás está decir que esta distinción se correspondería exactamente con la doble posición con que Luhmann caracteriza al sistema de la sociedad.

4) Juan Luis Pintos, a través de su concepto de 'Imaginarios Sociales', ha trabajado sobre este punto. El mismo señala: "Los imaginarios, en cuanto esquemas de representación, en cuanto contingencia de las propiedades en terminología luhmanniana, serían lo invisible". Ibid. p. 130

5) Ver apartado siguiente 'Autobservación e Interacción'

6) Recordemos la distinción propuesta por Maturana entre organización y estructura.

7) Sobre el concepto de 'acto unitario': Parsons, Talcott. La estructura de la acción social. Sobre el sistema social de la acción: Parsons, Talcott. Hacia una teoría general de la acción. Sobre este tránsito: Cousiño, Carlos. Razón y ofrenda. Cuadernos del Instituto de Sociología-PUC. Chile, 1990.

8) Nótese la similaridad formal de este concepto de memoria con el usado por Hannah Arendt en La vida del espíritu. En esta obra Arendt define memoria como la facultad del 
espíritu que permite en el presente la reconstrucción intencional de imágenes desensorializadas.

9 Me baso en una pequeña investigación que realicé para el curso 'Sociología de la Cultura' dictado por el profesor Pedro Morandé en el magíster en Sociología de la Universidad Católica de Chile, investigación que titulé: 'Precisiones sobre el concepto de estratificación y un análisis sobre los orígenes de la estratificación social en Chile'. 1999. 